NASA/TM-2005-213960

\title{
Fast Whole-Engine Stirling Analysis
}

Rodger W. Dyson

Glenn Research Center, Cleveland, Ohio

Scott D. Wilson

Sest, Inc., Middleburg Heights, Ohio

Roy C. Tew

Glenn Research Center, Cleveland, Ohio

Rikako Demko

Sest, Inc., Middleburg Heights, Ohio 
Since its founding, NASA has been dedicated to the advancement of aeronautics and space science. The NASA Scientific and Technical Information (STI) Program Office plays a key part in helping NASA maintain this important role.

The NASA STI Program Office is operated by Langley Research Center, the Lead Center for NASA's scientific and technical information. The NASA STI Program Office provides access to the NASA STI Database, the largest collection of aeronautical and space science STI in the world. The Program Office is also NASA's institutional mechanism for disseminating the results of its research and development activities. These results are published by NASA in the NASA STI Report Series, which includes the following report types:

- $\quad$ TECHNICAL PUBLICATION. Reports of completed research or a major significant phase of research that present the results of NASA programs and include extensive data or theoretical analysis. Includes compilations of significant scientific and technical data and information deemed to be of continuing reference value. NASA's counterpart of peerreviewed formal professional papers but has less stringent limitations on manuscript length and extent of graphic presentations.

- TECHNICAL MEMORANDUM. Scientific and technical findings that are preliminary or of specialized interest, e.g., quick release reports, working papers, and bibliographies that contain minimal annotation. Does not contain extensive analysis.

- CONTRACTOR REPORT. Scientific and technical findings by NASA-sponsored contractors and grantees.
- CONFERENCE PUBLICATION. Collected papers from scientific and technical conferences, symposia, seminars, or other meetings sponsored or cosponsored by NASA.

- SPECIAL PUBLICATION. Scientific, technical, or historical information from NASA programs, projects, and missions, often concerned with subjects having substantial public interest.

- TECHNICAL TRANSLATION. Englishlanguage translations of foreign scientific and technical material pertinent to NASA's mission.

Specialized services that complement the STI Program Office's diverse offerings include creating custom thesauri, building customized databases, organizing and publishing research results ... even providing videos.

For more information about the NASA STI Program Office, see the following:

- Access the NASA STI Program Home Page at http://www.sti.nasa.gov

- E-mail your question via the Internet to help@sti.nasa.gov

- Fax your question to the NASA Access Help Desk at 301-621-0134

- Telephone the NASA Access Help Desk at 301-621-0390

- Write to:

NASA Access Help Desk

NASA Center for AeroSpace Information 7121 Standard Drive

Hanover, MD 21076 
NASA/TM-2005-213960

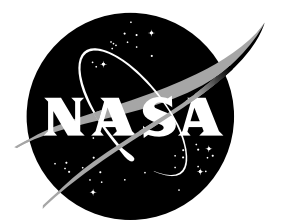

\section{Fast Whole-Engine Stirling Analysis}

Rodger W. Dyson

Glenn Research Center, Cleveland, Ohio

Scott D. Wilson

Sest, Inc., Middleburg Heights, Ohio

Roy C. Tew

Glenn Research Center, Cleveland, Ohio

Rikako Demko

Sest, Inc., Middleburg Heights, Ohio

Prepared for the

Third International Energy Conversion Engineering Conference sponsored by the American Institute of Aeronautics and Astronautics San Francisco, California, August 15-18, 2005

National Aeronautics and Space Administration

Glenn Research Center 


\section{Acknowledgments}

We'd like to thank Kumud Ajmani, Jim Heidman, Vijay Garg (deceased), and Isaac Lopez for their suggestions and guidance with high performance computing and simulation. The work described in this paper was performed for the Science Mission Directorate (SMD) and the Radioisotope Power System (RPS) Program, which provided funding for this project.

This report is a formal draft or working paper, intended to solicit comments and ideas from a technical peer group.

This report contains preliminary findings, subject to revision as analysis proceeds.

Trade names or manufacturers' names are used in this report for identification only. This usage does not constitute an official endorsement, either expressed or implied, by the National Aeronautics and Space Administration.

Available from

NASA Center for Aerospace Information 7121 Standard Drive

Hanover, MD 21076
National Technical Information Service 5285 Port Royal Road Springfield, VA 22100 


\title{
Fast Whole-Engine Stirling Analysis
}

\author{
Rodger W. Dyson \\ National Aeronautics and Space Administration \\ Glenn Research Center \\ Cleveland, Ohio 44135 \\ Scott D. Wilson \\ Sest, Inc. \\ Middleburg Heights, Ohio 44130 \\ Roy C. Tew \\ National Aeronautics and Space Administration \\ Glenn Research Center \\ Cleveland, Ohio 44135 \\ Rikako Demko \\ Sest, Inc. \\ Middleburg Heights, Ohio 44130
}

\begin{abstract}
An experimentally validated approach is described for fast axisymmetric Stirling engine simulations. These simulations include the entire displacer interior and demonstrate it is possible to model a complete engine cycle in less than an hour. The focus of this effort was to demonstrate it is possible to produce useful Stirling engine performance results in a time-frame short enough to impact design decisions. The combination of utilizing the latest 64-bit Opteron computer processors, fiber-optical Myrinet communications, dynamic meshing, and across zone partitioning has enabled solution times at least 240 times faster than previous attempts at simulating the axisymmetric Stirling engine. A comparison of the multidimensional results, calibrated one-dimensional results, and known experimental results is shown.

This preliminary comparison demonstrates that axisymmetric simulations can be very accurate, but more work remains to improve the simulations through such means as modifying the thermal equilibrium regenerator models, adding fluid-structure interactions, including radiation effects, and incorporating mechanodynamics.
\end{abstract}

\section{Nomenclature}

Porosity of the Medium

$\rho_{f} \quad$ Fluid Density

$\rho_{s} \quad$ Solid Density

$\vec{v} \quad$ Fluid Velocity Vector

$E_{f} \quad$ Fluid Energy

$E_{s} \quad$ Solid Energy

$h \quad$ Sensible Enthalpy

$J \quad$ Diffusion Flux of Helium

$k_{\text {eff }} \quad$ Effective Thermoconductivity

$p \quad$ Pressure

$S_{f}^{h} \quad$ Fluid Enthalpy Source Term

$T$ Temperature

\section{Introduction}

Great strides have been made in the last decade in expanding the designer's analysis options for building improved free-piston Stirling engines ${ }^{1}$ ranging from thermal and structural dynamic analysis, ${ }^{2,3}$ Computer-assisted-design (CAD) software for complete three-dimensional part 


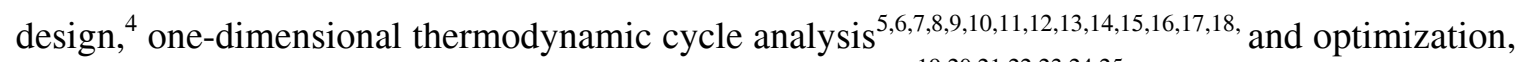
and one-dimensional system mechanodynamic simulation. ${ }^{19,20,21,22,23,24,25}$ A review of the progress in Stirling analysis shows a steady relaxation of assumptions/limitations imposed on the analysis over the past century. ${ }^{26}$

Initial two-dimensional computational fluid dynamic (CFD) simulation work began over twenty years ago and focused on specific regions of the engine but were not time-efficient and the projects were put on hold. ${ }^{6,27,28,29,30}$ And other researchers attempted to build specific in-house research codes with mixed success at modeling specific components. ${ }^{31,32,33,34,35,36}$

More recently, multidimensional multiphysics simulations that allow for realistic Stirling engine system solutions now exist and include the following capabilities that are potentially useful for Stirling convertor design: ${ }^{37,38,39,40}$

- Structural

- linear or nonlinear static or transient deformation

- modal, spectrum, harmonic, and random vibration dynamics

- linear or nonlinear buckling

- Thermal

- steady-state, transient, conduction, convection, and radiation

- $\mathrm{CFD}$

- Steady-state/transient, compressible/incompressible, laminar/turbulent, forced/natural convection, conjugate and radiation heat transfer, laminar to turbulent transition modeling, scalable parallel performance

- Electromagnetics

- electrostatics, magnetostatics, low-frequency electromagnetics, current conduction, circuit analysis, harmonic, transient, modal, scattering, perfect electric and magnetic conductors, impedence boundaries, near and far electromagnetic field extension, frequency selective surface, antenna radiation patterns, and specific absorption rate.

- Coupled Physics

- acoustics-structural, electric-magnetic, fluid-structural, fluid-thermal, electromagnetic-thermal, piezoelectric, piezoresitive, thermal-electric, thermal-structural, electromagnetic-thermal-structural, and eletrostatic-structural

Recently, attempts at utilizing these commercially available options have focused on only the thermal dynamic cycle simulation because it is difficult to achieve a useful solution in a reasonable time, let alone attempt a more comprehensive simulation. For example, previous attempts at whole engine simulation with these multiphysics commercial codes ended in unconverged solutions. ${ }^{31,41}$ Although a recent simplified axisymmetric solution ${ }^{75}$ shows reasonable energy balance convergence, the results are not validated yet by experiment.

The first reported successful three-dimensional whole Stirling engine simulation was reported by Mahkamov ${ }^{42,43,44}$ in the United Kingdom, but due to export control regulations, limited information and verfication is available. Apparently a gamma-type Stirling engine was simulated using commercially available software with good experimental agreement. It is not clear how much detail was simulated nor how practical the results are to engine design. The second reported successful three-dimensional Stirling engine simulation was by 
Zhang ${ }^{45}$ in China in which it took approximately 3 months to reach a steady-harmonic converged solution on a simplified, academic geometry that did not include the appendix gap, solid walls, or internal displacer.

A multi-dimensional analysis has an important place in Stirling engine design as is discussed at length in Ref. ${ }^{46}$ and outlined below:

- verify the one-dimensional results,

- properly simulate inherently three-dimensional turbulence-including transition,

- provide empirical heat transfer and friction factor coefficients for complex geometries before the hardware is built

- integrate all the parts into a CAD system and test for structural and relative motion issues in the overall design

- assist experiments with determining hard to reach data

- provide a fluid-structure interaction capability

- generate linear reduced order models for controller development

- solve high-power Stirling applications in which the one-dimensional flow assumption breaks down

- identify areas of excessive flow losses due to unintended dead zones, recirculation zones, dissipative turbulence and other losses such as: ${ }^{47,48,49}$

1. Inefficient heat exchange and pressure loss in the regenerator, heater and cooler,

2. Gas spring and working space loss due to hysterisis and turbulence,

3. Appendix gap losses due to pumping and shuttle effects,

4. Mixing gas losses from nonuniform temperature and flow distributions perpendicular to primary engine flow axis,

5. Conduction losses from the hot to cold regions

6. Losses due to combined radiation, conduction and convection in hollow spaces

7. And in general, inaccurate loss representations due to use of 1-D flow design codes to account for flow and heat transfer through area changes (between components) where phenomena such as flow separation and jetting from tube into regenerator may occur.

The current multiphysics simulation tools are not optimized for Stirling analysis as discussed in Ref. ${ }^{50}$ For example, recently developed oscillating time advance strategies ${ }^{51,52,53,54,55,56,57}$ and high order spatial differencing could make modeling oscillating turbulent transition a reality. But given the cost of developing new codes, it is desirable to fully utilize current technology first.

This paper will present the first successful U.S. axisymmetric Stirling engine simulation incorporating an actual engine's geometry including appendix gap, displacer seals (inner and outer), solid walls, and displacer interior. Only the flexures, piston seals, bounce space, radiation shields, and heat exchanger fins were not included for this initial work, but reasonable agreement with experiment has been achieved despite these omissions.

\section{Description of the Problem}

The dual opposed configuration shown in figure $1^{58,59,60,61}$ is being developed for multimission use (i.e., for use in atmospheres and space), including providing electric power for potential missions such as unmanned Mars rovers and deep space missions. ${ }^{62,63}$ 
Only the Stirling engine part of the convertor (Fig. 2) is simulated multi-dimensionally although one could anticipate the entire convertor may one day be simulated using modified multiphysics software.

An example of the desired full Stirling engine simulation is shown in Fig. 3. It is anticipated that full 3D simulations will provide a level of geometric and flow detail necessary for further design improve-

ments. For example, hardware experiments have shown that large performance gains can be made by varying manifolds and heat exchanger designs to improve flow distributions in the heat exchangers. ${ }^{59,64,65,66}$

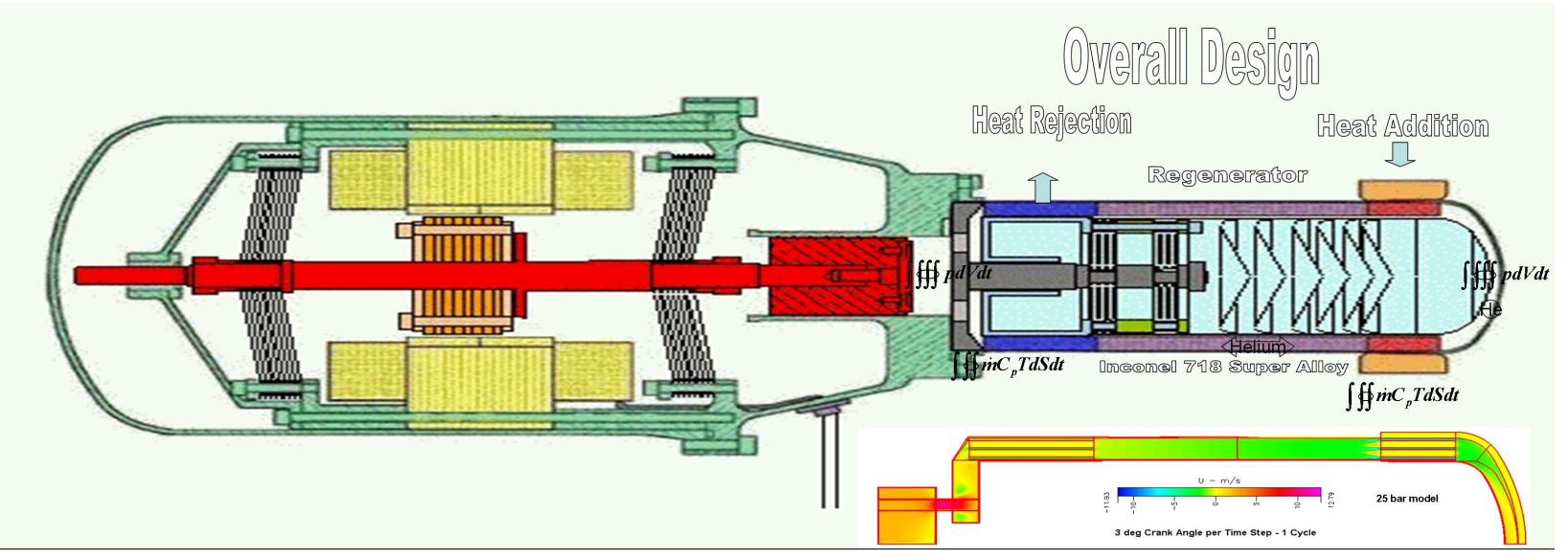

Figure 2. Stirling Engine Part of Convertor Simulated Only

The kinds of flow and geometry that occur in a Stirling engine for which a modeling technique must address are as follows: ${ }^{49,48}$

1. Oscillating flow which changes the effective conduction, flow friction coefficients and heat diffusion. ${ }^{67}$

2. Low mach number flow (no shocks),

3. Compressible flow due to enclosed varying volumes and heat transfer effects,

4. Laminar, Transitional, and Turbulent flow with Reynolds numbers from 100 to 10000 (based on various length scales pertinent to the flow region),

5. Conjugate heat transfer, thermal dispersion and local thermal nonequilibrium in the porous media regenerator,

6. Micron to Millimeter scale geometry ${ }^{6}$

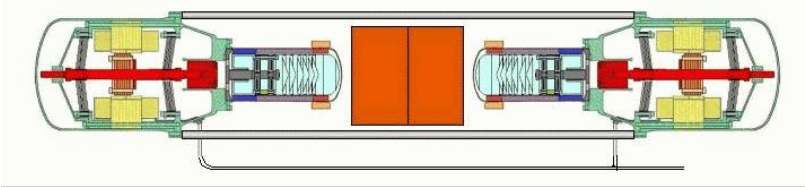

Figure 1. Dual Opposed Stirling Convertors Reduce Vibration (Schreiber) 
7. Sliding Interfaces in the appendix gap

8. Deforming Flow Regions Due to Compression and Expansion

\section{Current Multi-Dimensional Stirling Cycle Analysis Tools}

At the level of multidimensional analysis, relatively little has been completed because the third order analysis, including Sage, ${ }^{5}$ and to some extent, DeltaE, ${ }^{13}$ and MS*2 Stirling Cycle Code ${ }^{11}$ are faster and for the most part have been adequate engineering design tools. However, to improve efficiency, reliability, and supplement experimental testing (to understand and reduce losses, identify component temperatures, assist in sensor calibration, correlation, and placement) it will likely require a better understanding of the actual flow features and heat transfer throughout the engine. Some of the primary multidimensional analysis tools are shown below.

\section{Modified Computer Aided Simulation of Turbulence (CAST)}

The modified CAST code $^{69}$ is based upon the Semi-Implicit Method for Pressure-Linked Equations (SIMPLE $)^{70}$ method but is restricted to two dimensions. ${ }^{71,72,73}$ It was modified to include oscillatory boundary conditions and conjugate heat transfer but does not allow for complicated geometry nor sliding interfaces. It has been used to model Stirling components but has not been extended to a whole engine simulation tool.

A pressure-splitting technique was added ${ }^{74}$ to reduce the computational requirements. It was based on separating the thermodynamic and hydrodynamic pressures so that these widely varying scales could be solved with less round-off error and better efficiency. And the non-acoustic form of the equations was later incorporated into the code since the fast acoustic waves and small dimensions of the engine essentially resulted in "incompressible" like flow behaviour and removing the acoustical pressure disturbance could enhance computational speed and accuracy. ${ }^{32}$

\section{2. $C F D-A C E$}

This commercial code has been used to model a two-dimensional representative Stirling engine ${ }^{31,75,33,45}$ and it has been used to model an actual engine. ${ }^{41}$ Full validation of these simulations has not been completed.

It is also based upon the SIMPLE technique. The regenerator is not currently modeled correctly since thermal equilibrium is assumed between the gas and solid, but as shown later, this error may not be large compared to the overall engine performance. The code does support sliding interfaces on parallel computers in three-dimensions and the company is introducing sliding, overlapping Chimera grids which should enable better appendix gap modeling. Moreover, the highly compressed volumes occuring at both ends of the displacer may be more easily modeled with Chimera grids. This finite volume code can utilize both structured and unstructured grids.

\section{Fluent}

This commercial code is based upon the SIMPLE and PISO methods. It currently has similar regenerator modeling limitations as CFD-ACE. It does however have a sliding interface for two-dimensional axisymmetric flows that can be used for appendix gap modeling on parallel computers and will be discussed in more detail later. It is also finite volume based and can utilize both structured and unstructured grids.

It has been used with mixed success by industry for Stirling engine simulations ${ }^{76}$ by several commercial manufacturers. It was also used by Mahkamov ${ }^{43}$ in what appears to be the first full three-dimensional simulation, but details are embargoed. Also, in the related business of cryocooler modeling it has been used with reasonable success on simplified problems ${ }^{77,78,79,81,82,83,84,85,86,87,88}$ And this report has utilized it to provide a detailed axisymmetric simulation. 


\section{STAR-CD}

The Simulation of Turbulent Flow in Arbitrary Regions (STAR) ${ }^{38}$ code also uses SIMPLE and PISO methods. Its companion product (STAR-HPC) is the parallel computer version. It also has sliding interfaces and deforming mesh capability. It has been used in the related field of internal combustion engine piston modeling, and some Stirling engines and regenerators have been modeled with it. ${ }^{89,90}$

\section{5. $C F X$}

This code also uses SIMPLE and PISO methods on unstructured grids. It also has sliding interfaces implemented, but no stirling engine modeling with this software has been publicly published. ${ }^{37}$ It currently seems to have the greatest potential for full multiphysics Stirling convertor simulations because of it's fluid-structure interaction, magnetic flux analysis, and structural/thermal stress analysis capabilities. It's dynamic meshing capabilities are not ideal for highly compressed volumes as occur in the Stirling engine since only the spring analogy mesh adaption is currently available.

\section{Others}

While there are other research codes, they are usually limited to modeling only specific regions of the Stirling engine such as the regenerator, or the displacer. ${ }^{80,81,15,91,92}$

\section{Regenerator Modeling}

A very important specific area of modeling difficulty is the regenerator. Since the regenerator (depending upon one's definition of effective) has roughly 3 to 40 times more effective heat transfer than the heater, ${ }^{93}$ any inefficiency of the regenerator represents a significant loss for the entire Stirling engine. Hence, any numerical losses or inaccuracies in this region will disproportionately influence the entire Stirling simulation.

Also, the geometrical shape of the matrix elements in the regenerator is important and as shown in Figs. 4(b-f), many shapes are possible. For practical calculations a Representative Elementary Volume (REV) is often used as shown in Fig. 4(a). An REV requires some closure assumptions that can be partially derived from experiment and potentially from microscale (pore level) numerical simulations.

Since the size and shape of the regenerator fibers do affect Stirling engine performance, numerically simulating a regenerator has been pursued at both microscopic (direct) and macroscopic (REV) levels of fidelity. ${ }^{6,94,95,96,97,98,99,100}$ An example simulation utilizing Fluent by Harvey from Georgia Tech is shown in Fig. 5.

However, our initial approach at whole engine simulation simply adds source terms to the governing equations and does not take into account the different temperatures of the solid matrix and the fluid. The source terms serve to enforce a pressure drop according to the Darcy-Forcheimer ${ }^{67}$ equation. And only a single energy equation is used, although it does include an effective solid/fluid average conductivity ${ }^{68}$ and an effective solid/fluid average energy.

The continuity equation is not modified, but the following source term is added to the momentum equations (for $i=x, y$, or $z$ ):

$$
S_{i}=-\left(\frac{\mu}{K} v_{i}+C_{2} \frac{1}{2} \rho v_{m a g} v_{i}\right)
$$

where permeability $K=4.08 e^{-10} m^{2}, C_{2}=\frac{2 C_{f}}{\sqrt{K}}$ and inertial coefficient, $C_{f}=0.178$. These coefficients were determined experimentally ${ }^{101}$ and used without modification here. And the fluid/solid averaged energy equation can be written as: 


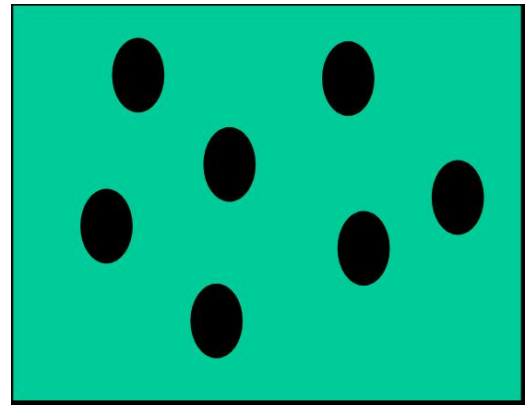

(a) Representative Elementary Volume

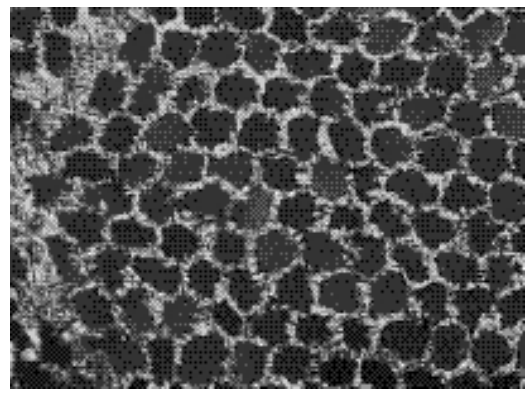

(d) Perforated Disk

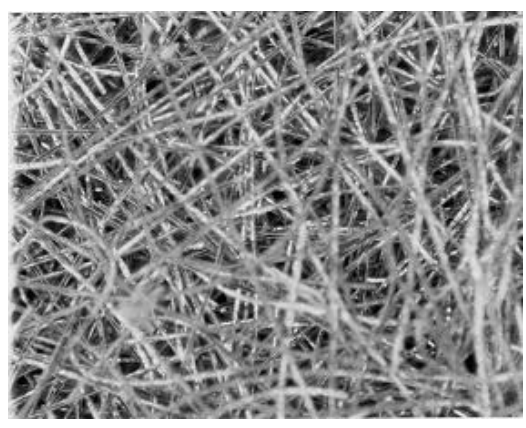

(b) Random

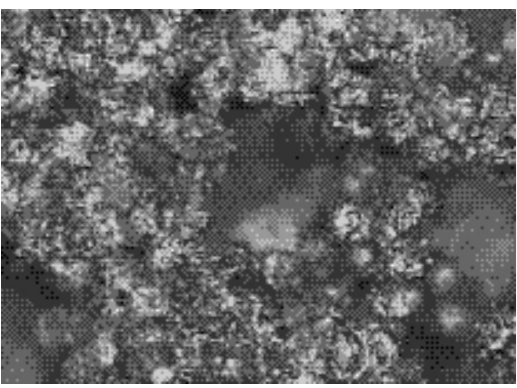

(e) Foam Metal

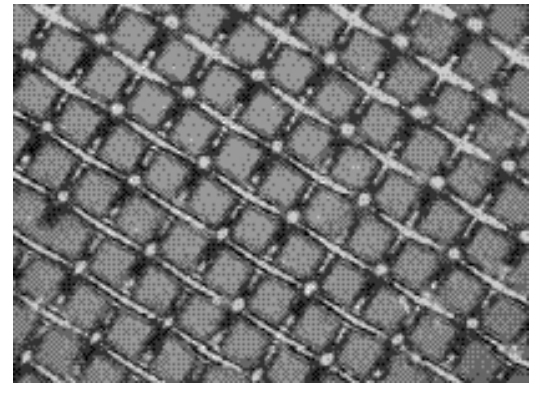

(c) Wire Mesh

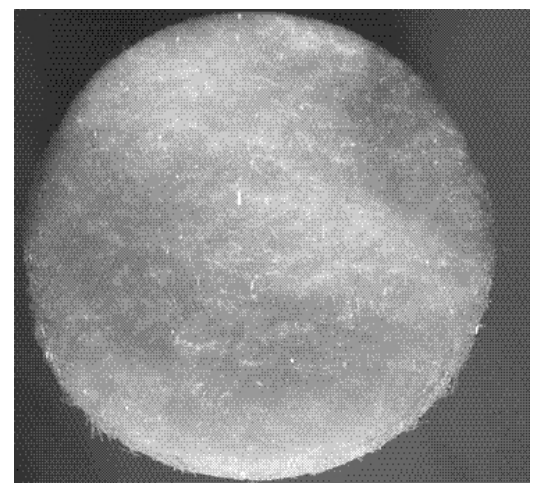

(f) Sintered Glass (Failed)

Figure 4. Regenerator Geometry

$$
\frac{\partial}{\partial t}\left(\gamma \rho_{f} E_{f}+(1-\gamma) \rho_{s} E_{s}\right)+\nabla \cdot\left(\vec{v}\left(\rho_{f} E_{f}+p\right)\right)=\nabla \cdot\left[k_{e f f} \nabla T-\left(\sum_{i} h_{i} J_{i}\right)+(\hbar \tau \cdot \vec{v})\right]+S_{f}^{h}
$$

\section{Dangers of Component Modeling}

Modeling the entire engine, as demonstrated herein, is preferable to modeling one component at a time due to the oscillatory nature of the flow. A component requires known unsteady boundary conditions for an entire cycle. Since a given boundary may have flow going in both directions, the direction of the characteristics at these boundaries are difficult to define. Incorrect specifications of boundary conditions result in solution instability, nonconvergence of solutions, and/or convergence to inaccurate results. It is well known that even for steady harmonic flows, non-physical reflections can occur at inflow and outflow locations. ${ }^{102}$ In essence, by artificially truncating the domain to model a single engine component an artificial boundary condition is required. However, the exact specification of artificial/non-reflecting boundary conditions in nonlinear turbulent flow is an important and as yet unresolved area of research. ${ }^{103}$

For example, a subsonic inflow has four characteristics entering and hence four physical boundary con- 


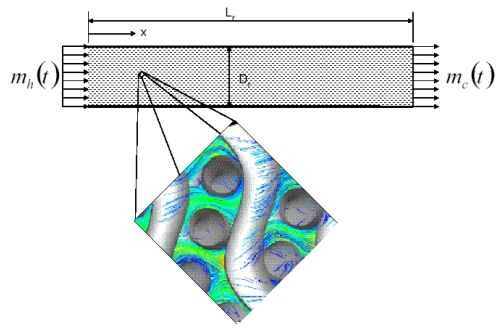

(a) Schematic

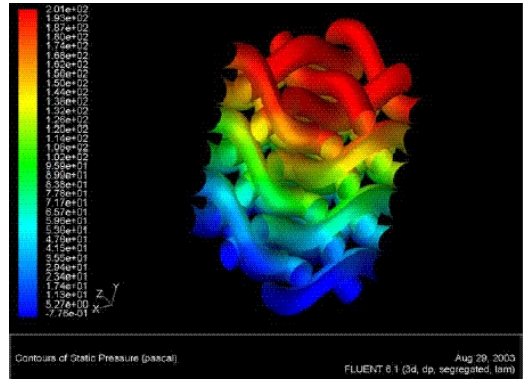

(b) Pressure

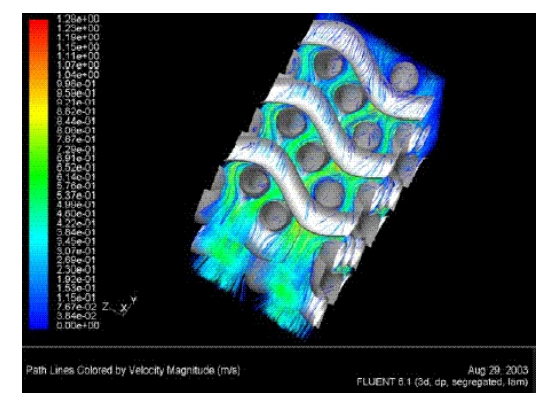

(c) Pathlines

Figure 5. Flow Through Wire Mesh Screen Regenerator

ditions need to be specified, typically total pressure, total temperature, and two flow angles, allowing only one of the velocity components to be free (which is extrapolated from the interior flow solution). A subsonic outflow has only one characteristic entering and hence only one physical boundary condition should be specified, for example, static pressure.

Simultaneous inflow/outflow along each engine component's interface is clearly demonstrated by examining flow velocities near zero (from $-1 \mathrm{~m} / \mathrm{s}$ to $1 \mathrm{~ms}$ ). Regions of blue and red in Fig. 6 show borders of mixed inflow/outflow in the axial direction. For example, the piston compression space in Fig. 6(a), the seal exit in Fig. 6(b), the cooler exit in Fig. 6(c), and the appendix gap entrance in Fig. reffig:oscillating(d) all show mixed inflow/outflow borders at this moment in time. Moreover, these mixed boundaries moving during the cycle, further complicating the numerical boundary treatment. If a component boundary crosses any of these indicated areas, the boundary conditions will not be properly defined. Of course in the case of commercial software users the code will attempt to stabilize the solution with essentially guessed boundary conditions, but the solutions will be inherently non-physical.

Repeating the same velocity test, but this time examining velocity close to zero in the y-direction, we see a new set of boundary lines that will pose difficulties resulting in non-physical component solutions in Fig. 7 .

\section{A. Adjust Components within a Full Engine Simulation}

Instead of pursuing the mathematically ill-posed problem of component modeling in complicated oscillating flow, it is easier, more efficient, and more reliable to determine a whole engine steady-harmonic solution with the procedures described herein. The engine components can be easily examined and it only takes a few hours to test the effect of component changes since the overall engine has the correct steady-harmonic temperature distribution.

At the same time, it is possible to numerically determine the one-dimensional equivalent friction factors and heat transfer terms in the new components required by one-dimensional analysis tools (e.g. Sage). In this way, a one-dimensional analysis be made more accurate while not requiring the ill-posed boundary conditions that multidimensional component modeling entails. ${ }^{46}$ Finally, it is worth noting that one-dimensional analysis does not have difficulty with component modeling because a boundary is always either an inflow or an outflow, never both. 


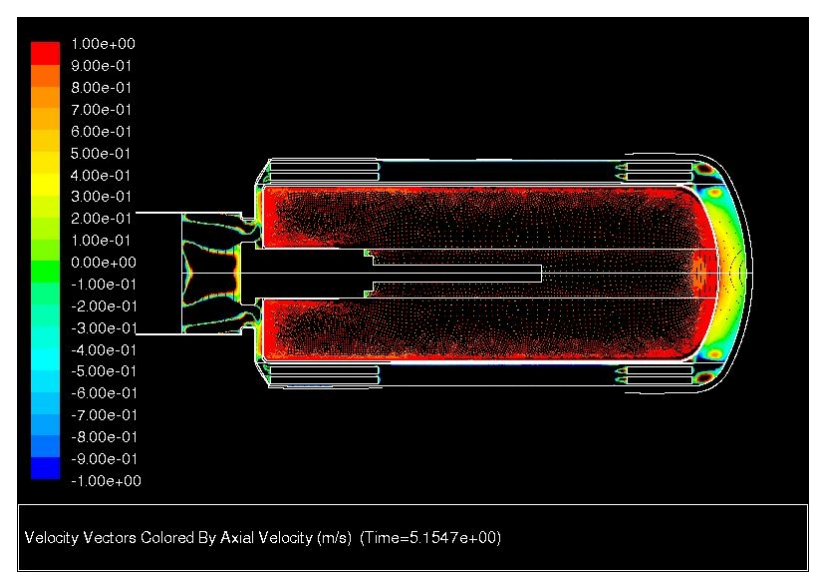

(a) Entire Engine

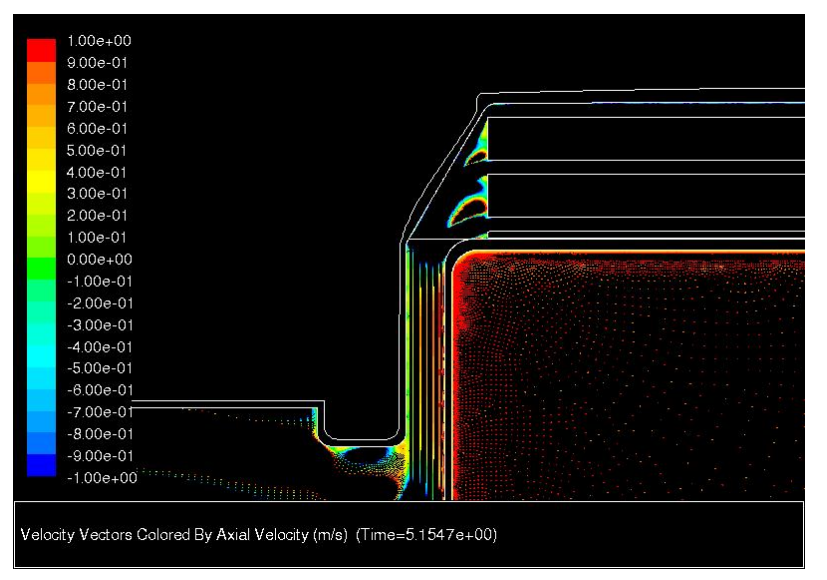

(c) Compression Space

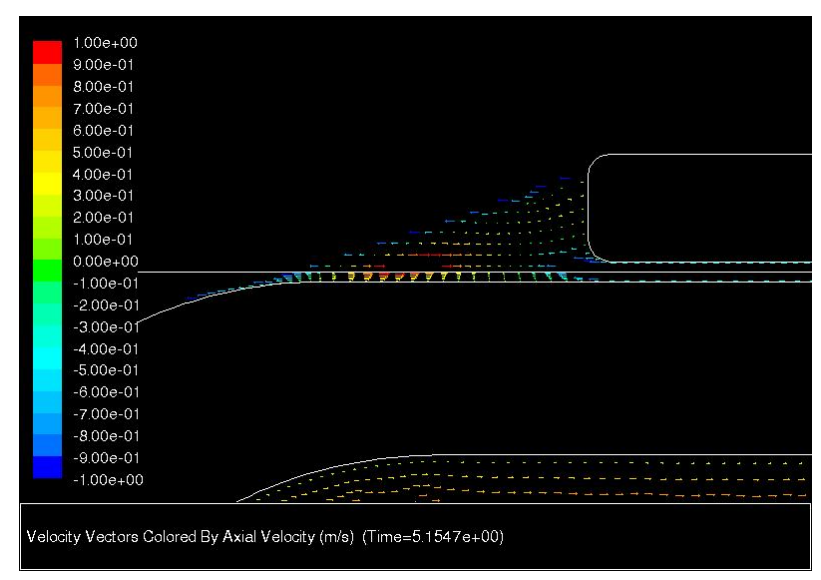

(b) Seal Region

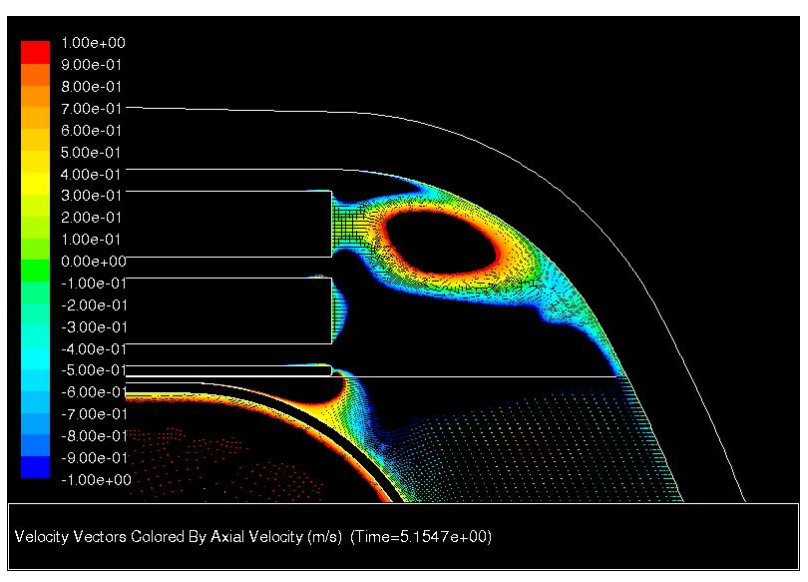

(d) Heater Manifold and Appendix Gap

Figure 6. Oscillating Axial-Direction 


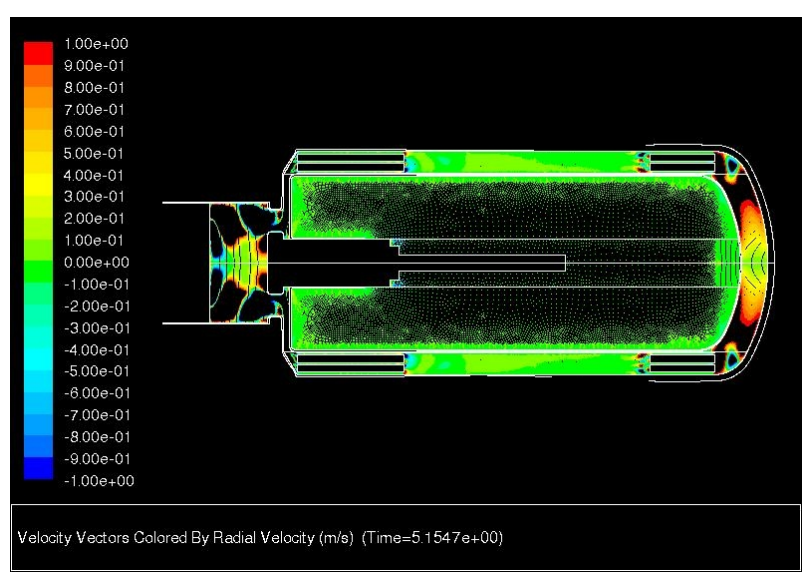

(a) Entire Engine

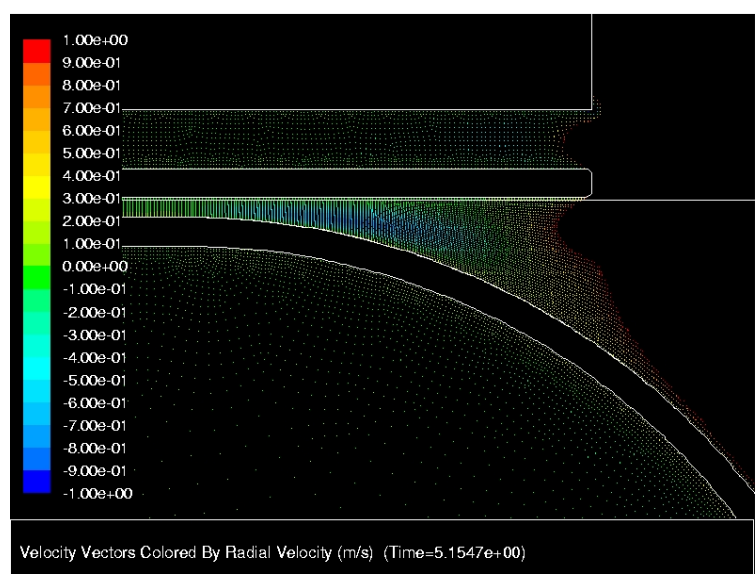

(c) Appendix Gap Region

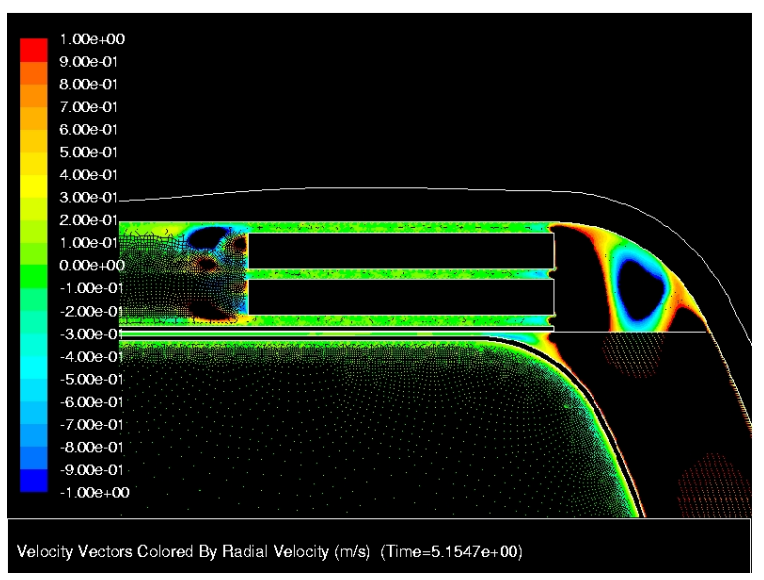

(b) Heater Region

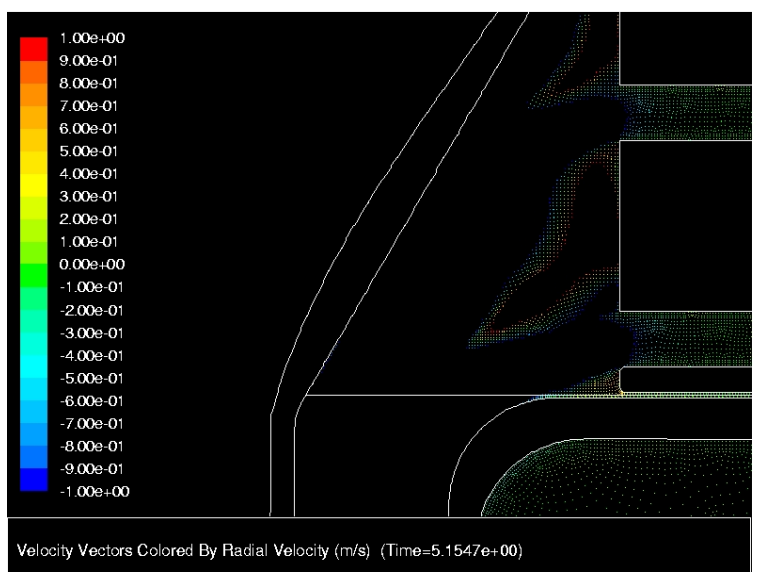

(d) Seal Region

Figure 7. Oscillating Radial-Direction 


\section{Approach for Fast Simulations}

Achieving practical computer simulations of entire Stirling engines depends upon judicial use of computer hardware, software engineering, grid generation, and algorithm design. A combination of all four areas is presented next that enables axisymmetric whole engine simulations to be accurately completed in less than a week.

\section{A. Computer Design}

An important area new to Stirling analysis is the use of parallel computers for faster simulations. NASA Glenn was one of the first organizations to pioneer computer clusters back in 1992. Many universities have assembled their own low cost computers, ${ }^{104}$ and many states have supercomputer consortiums ${ }^{105}$ to assist in designing and operating small computer clusters that utilize commercial off-the-shelf (COTS) hardware and software for low cost systems. These systems are referred to as Linux Beowulf clusters ${ }^{106,107}$ and now represent the majority of the top 500 supercomputer systems in the world. ${ }^{108}$ Recently, many commercial organizations have begun assembling "Beowulf"-like clusters including Dell, ${ }^{109}$ Angstrom, ${ }^{110}$ LinuxNetworx, ${ }^{111}$ Appro, ${ }^{112}$ and Microway ${ }^{113}$ as shown in Fig. 8. They cost a bit more, but provide comprehensive health monitoring and controls that significantly reduce the adminstration and integration costs. The latest systems can house 260 processors in a single 7 foot tall tower.

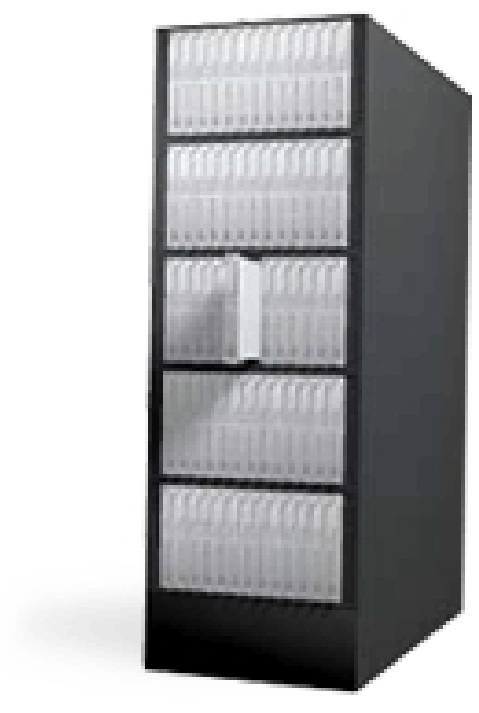

(a) Angstrom Cluster

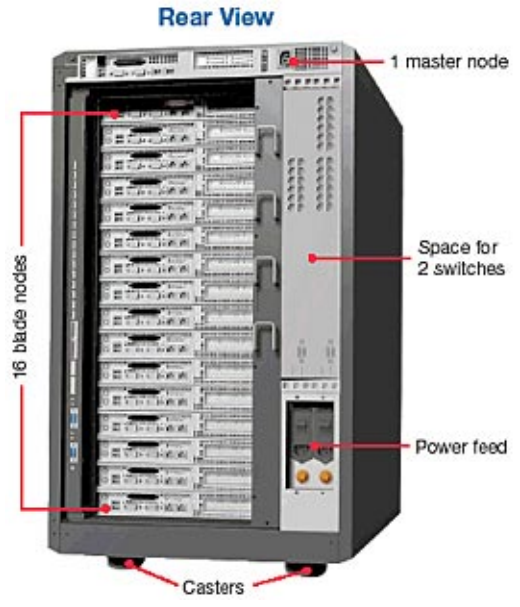

(b) Appro Cluster

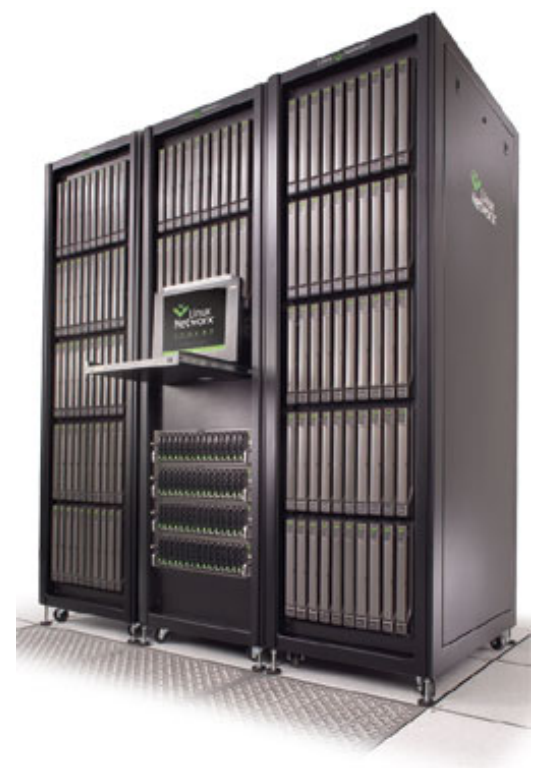

(c) Linux Networx Cluster

Figure 8. Appro, Angstrom, and Linux Networx Clusters

Our sixteen dual-Opteron (32) processor Microway cluster is shown in Fig. 9. This was selected because last year it represented the best value for performance and it integrated well with the commercial software, Fluent. The Opteron chip, at the time, was the only chip that could run 32-bit and 64-bit applications with an exceptional price/performance ratio. All the whole Stirling engine results shown here were calculated using it.

A very important consideration when designing your computer cluster is the communication bandwidth and latency since commercial fluid simulation software utilizes older numerical approaches that require a large 


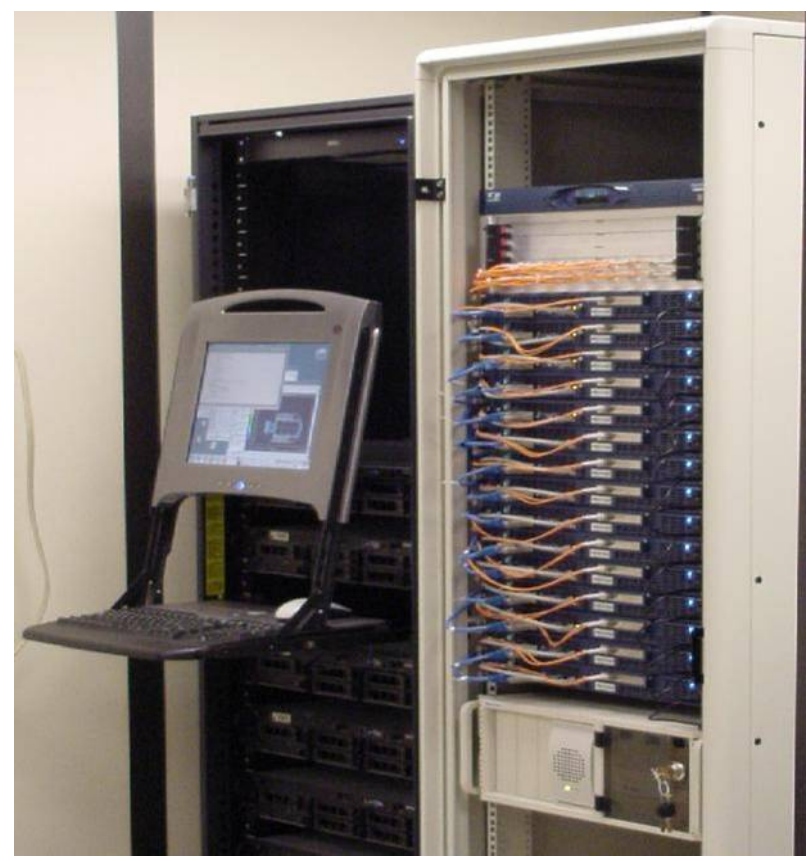

(a) Front View

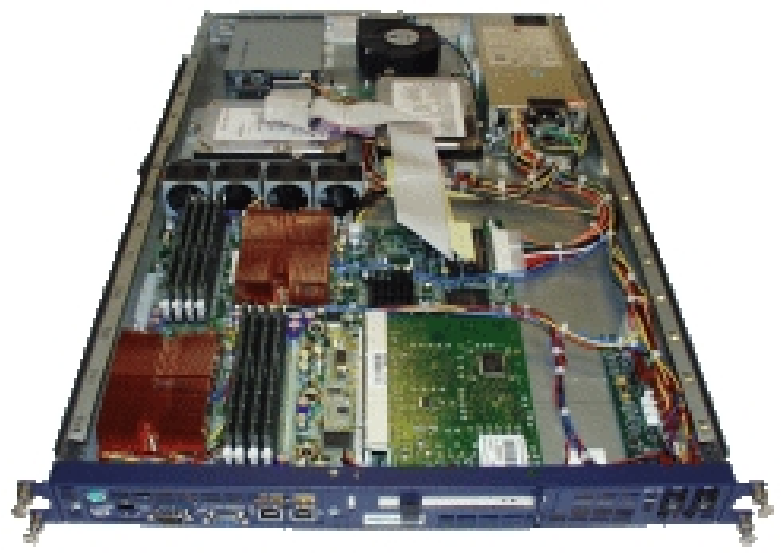

(b) Dual CPU Board

Figure 9. Microway Cluster

number of frequent communications between the compute nodes. In Fig. 10, two of the best communications network interface card (NIC) and network switches are shown. The Infiniband system can perform $10 \mathrm{~Gb} / \mathrm{s}$ bi-directional communication rates or about 20 times faster than the Myrinet in our cluster. Our simulation utilized Myrinet communications because last year Infiniband was not a proven technology.

\section{B. Software Decision}

We chose Fluent as our computational platform because, at the time, it was the only commercial vendor supplying an axisymmetric sliding interface for parallel computers. Presently, as mentioned in Sec. III, the other vendors are now also providing similar capability. It is important to always have at least two commercial solvers available because of the invariably large number of bugs in their software. Generally, a bug is more easily found if the same simulation is repeated with two different codes. For example, Fluent version 6.1.22 properly handles heated moving solids, but the new release (version 6.2.16) did not as identified by Ibrahim. ${ }^{114}$ The latest version 6.2 .19 has been corrected.

Another reason for utilizing at least two commercial codes is the lack of control the user has in the solvers utilized. Generally, the commercial codes all utilize slight variants of older, well established lower order numerical techniques. The slight variants are the only independent way to examine the effect of a given solver and to look for possible defects. Of course developing one's own software offers more freedom, but this can be risky in the short-term.

Our second platform utilizes CFD-ACE and reasonable solutions have been achieved with it. It's primary limitation has been the need to work in three-dimensions when solving cases including axisymmetry sliding interfaces. Another strength of this software is it includes a wide range of multiphysics capabilities.

A third very interesting platform is CFX because of it's integrated multiphysics capability enhanced by 


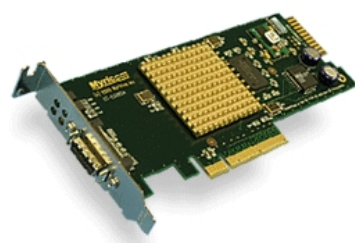

(a) Myrinet Card

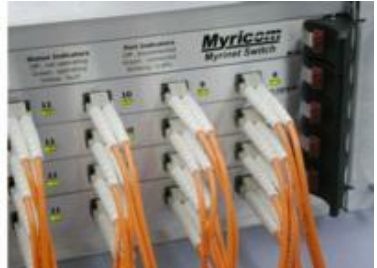

(b) Myrinet Switch

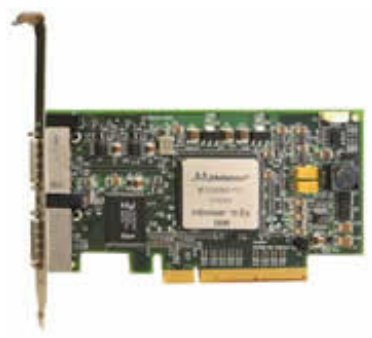

(c) Infiniband Card

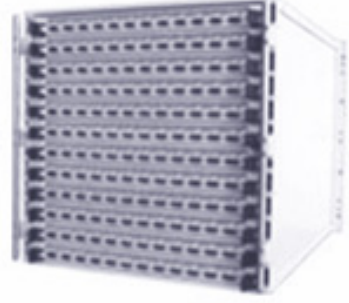

(d) Infiniband 144 port Switch

Figure 10. Communications

the merger between ANSYS and CFX. The only apparent limitation of the software is grid layering is not yet available. Grid layering is defined by the automatic addition or removal of a row of cells as the mesh domain shrinks or expands and will be discussed later.

Other packages such as STAR-HPC are very capable as well. However, the commercial cost of these packages are very expensive and it is not practical to test all of them.

Finally, full three-dimensional simulations are still quite challenging and the parallal scalability of the commercial software is somewhat limited due to the implicit nature of their steady flow solvers. Better approaches are currently available ${ }^{50}$ but have not yet been applied to the Stirling cycle analysis.

\section{Grid Design}

When using commercial codes, it is primarily the grid quality that determines the speed and accuracy of the solution. Ideally, one could simply read in a three-dimensional CAD geometry and a grid would automatically be created. That is in fact the implied goal of computational fluid dynamics code developers. But for complicated geometry as occurs inside a Stirling engine with all it's moving parts, the technology currently available still requires a great deal of human intervention. Taking several weeks to develop a grid is not unusual and is often required to get a reasonable solution. For example, the rate at which conjugate heat transfer can be solved is directly related to the smoothness and quality of the grid at the interface. This is particularly true in Stirling engines when the heat capacity of the solid is vastly diffent than the Helium. If short-cuts are taken in developing the grid, the price is often vastly longer solution times, if a solution is produced at all.

All the grids produced in this work were done with Gambit, which is the Fluent,Inc. proprietary grid generator. There are other grid generators available with their own distinct advantages, but despite the bugs encountered in Gambit, we found it to be a useful tool.

First, the domain is scaled up by 1000 to compensate for the 32-bit precision available in the grid generator.

The Stirling engine, when entirely modeled, has a fairly wide range of length scales ranging from a thousandth of an inch in the narrow seal and appendix gap region to an inch or more in the heat exchanger regions. This scaling has the effect of making very small numbers larger so that smoother grids can be created. Once the mesh is created satisfactorly, the entire grid domain is scaled back down by a 1000 before utilizing it.

Second, try to use structured or paver unstructured grids wherever possible to reduce the number of bad cells and to reduce the number of cells required. Avoid unstructured tetrahedrals because of the considerably reduced rate of solution convergence. 
Third, be sure a sliding interface has essentially matching cell sizes on both sides of the interface to prevent interpolation errors and avoid instabilities.

Fourth, be sure to place grid points in the boundary layer to properly model friction losses.

Fifth, use sizing functions to smoothly expand the cell size from the boundaries at a rate of 10 percent.

Sixth, use layering wherever possible, but avoid grid adaption and remeshing because this slows down the solution time considerably. Choose a layering size large enough to permit a reasonable 160 time steps per cycle, but small enough to allow for smooth transitioning to boundary layers.

Seventh, utilize moving boundary layers on all walls that are moving to enhance conjugate heat transfer. And place a boundary layer on both sides of the interface (on the solid side and the fluid side).

Eighth, include as much geometry as is practical to avoid having to redo the grid later when simplifying assumptions are found to matter.

Ninth, clean up the geometry first in a CAD package to avoid creating virtual geometry that is not as robust.

Tenth, test your grid by forcing the piston and displacer to be stationary and simulate the heat transfer in the engine. Once a converged solution is observed, continue running the solver and look for grid induced heat sources. It should be noted that Cleveland State University found producing a steady-state result first provided a better starting condition for the transient solution. But this last suggestion goes a bit further in providing a means for improving the grid by "over-converging" the steady solution.

For the successful case presented here, we used about 700,000 grid points and all grid boundary layers start at a distance of .001 in from the fluid/solid interface.

In Fig. 11, we show the entire engine, piston region and spider region grid utilized in this simulation. Notice the piston has a moving boundary layer and grid layering is used to avoid small cells when the piston fully compresses. Also, notice in the spider region that all helium/wall interfaces have boundary layers on both sides to enhance conjugate heat transfer. The overall engine can be seen to not include any grid inside the heater or cooler since the heat exchanger wall temperture is specified as constant. Also notice there is some extra wasted grid in the spider region near the compression space. This is necessary to maintain grid quality in the other nearby boundary layer regions. Grid quality is more imporant than grid count for faster conjugate heat transfer calculations.

In Fig. 12, the hot half of the engine is shown, including the gridding in the displacer and appendix gap. Notice that despite the complexity, tetrahedral grids were not required. The layering inside the displacer was done to avoid moving all the grid points inside the displacer for faster run-times. For example, without grid layering (the addition or subtraction of rows of cells), all the grid cells inside the displacer would need to move. Instead, only the single layer of cells located at the top of the displacer (right side in picture) moves at a time in Fig. 12(b). Also, the expansion space uses layering to avoid skewed cells when the displacer is at top dead center (TDC).

In Fig. 13, the gridding utilized in the seals and compression space are shown. The challenge in the seal region is to avoid overly skewed cells, overly mismatched cells across the interface, and reasonable cell size variation near the boundary layer. It is quite difficult to balance all these constraints. Layering was used in the compression region to avoid crushed cells and the axial direction spacing was chosen to maximize the time-step.

In Fig. 14 the seal inside the displacer is shown. Notice the use of unstructured quadrilaterals throughout to avoid the inefficient tetrahedral gridding. Also notice just how small the seal gap is even compared to the thickness of the displacer wall. This region was very difficult to grid and required utilizing suggestion 10 in Section C. Velocities are high in this region and this grid may not be adequate here, but since this seal region is not being studied this was left as seen. 


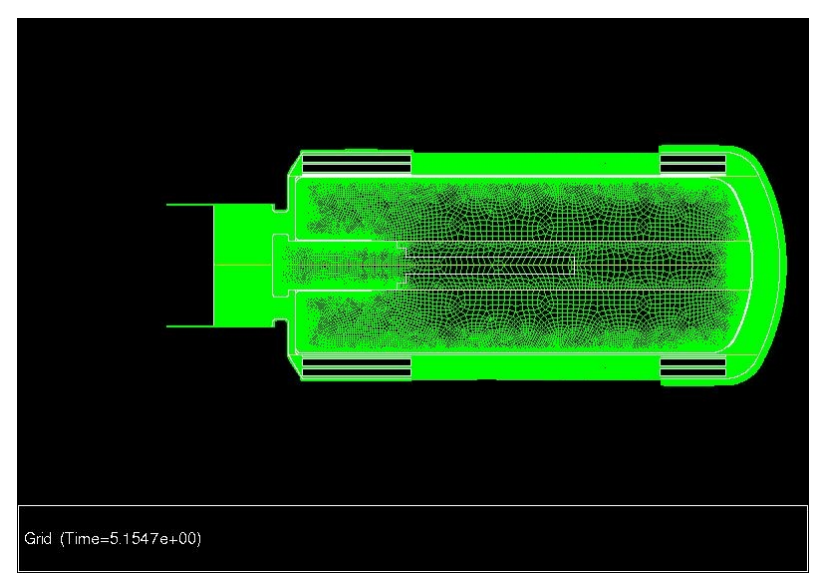

(a) Entire Engine

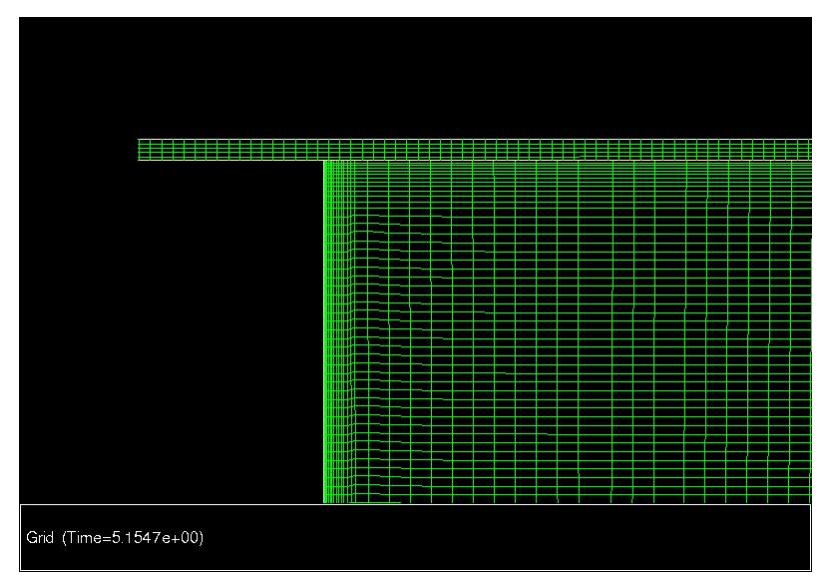

(b) Piston Region

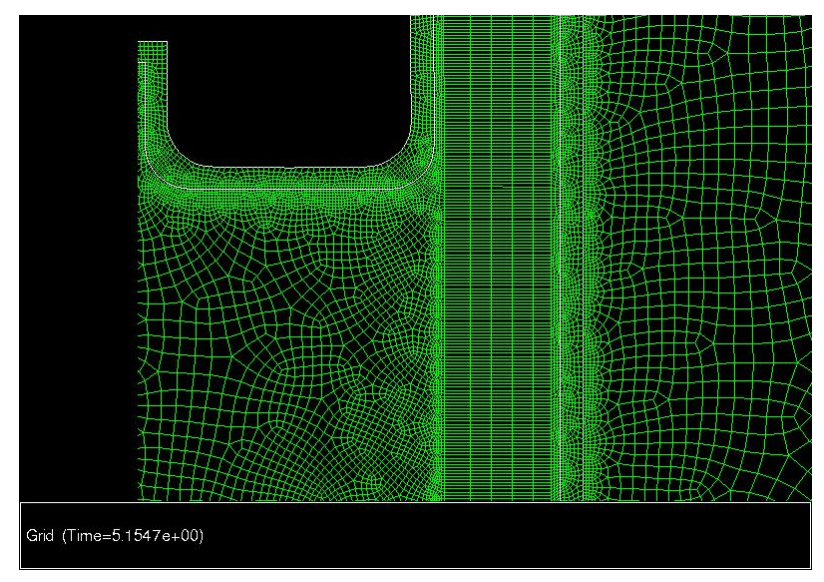

(c) Spider Space

Figure 11. Grid Strategy 


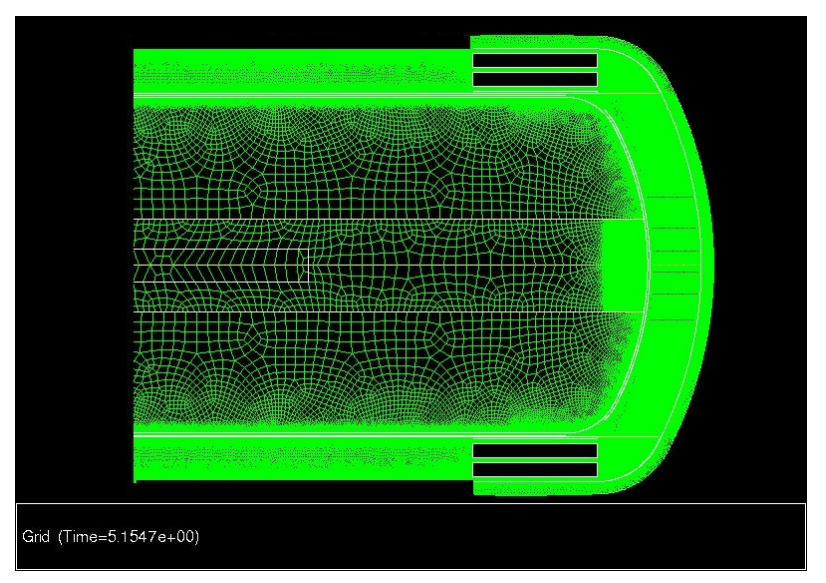

(a) Right Half

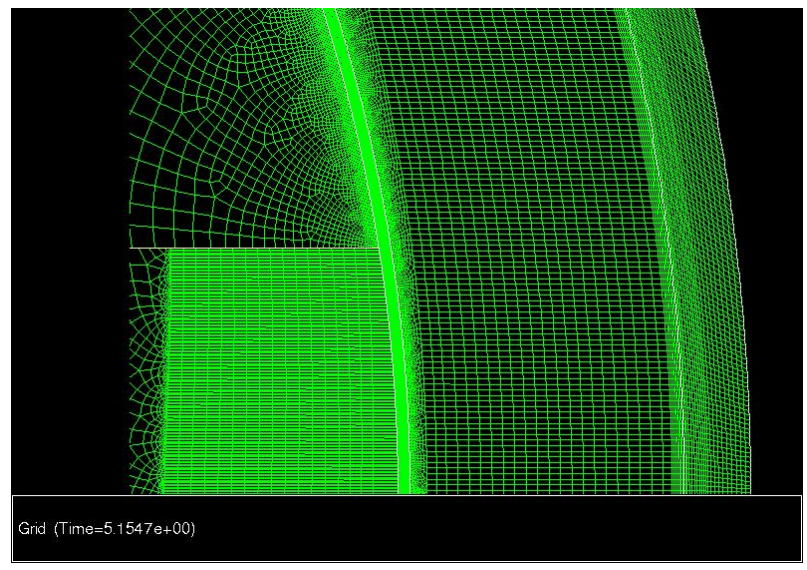

(c) Layering in Expansion Space

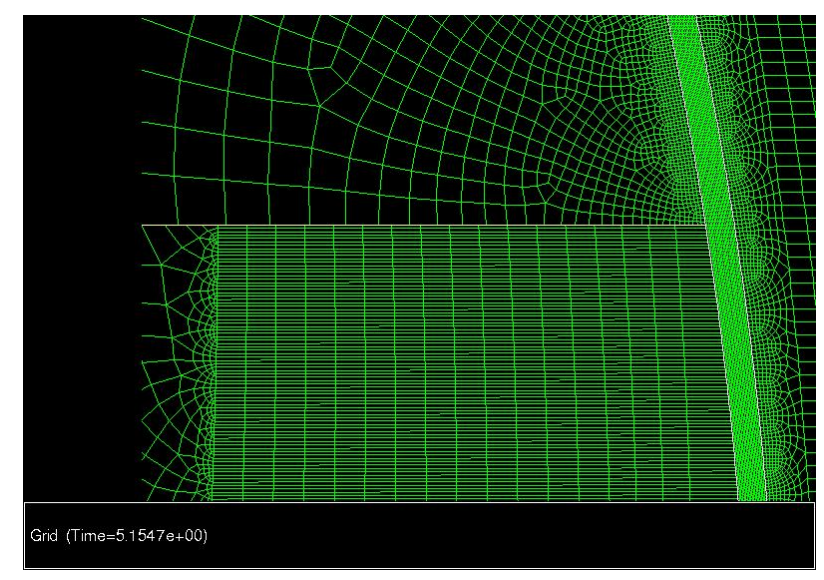

(b) Layering Inside Dome

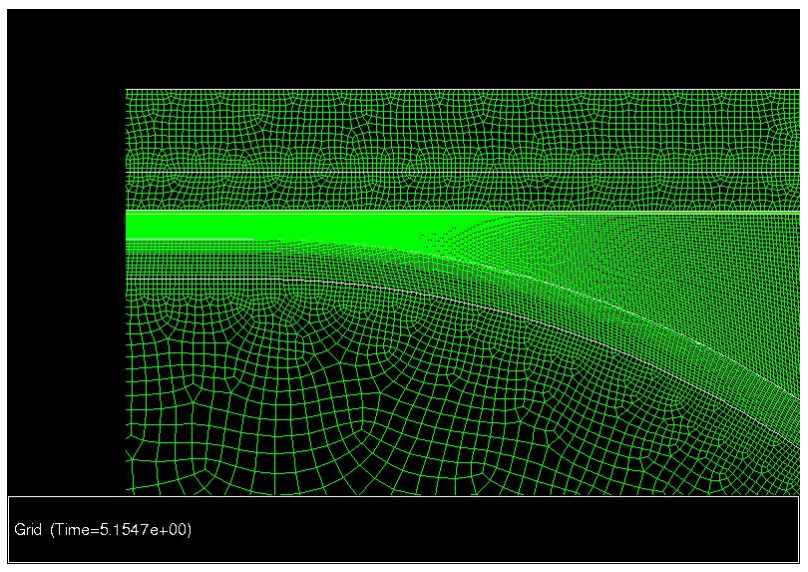

(d) Appendix Gap

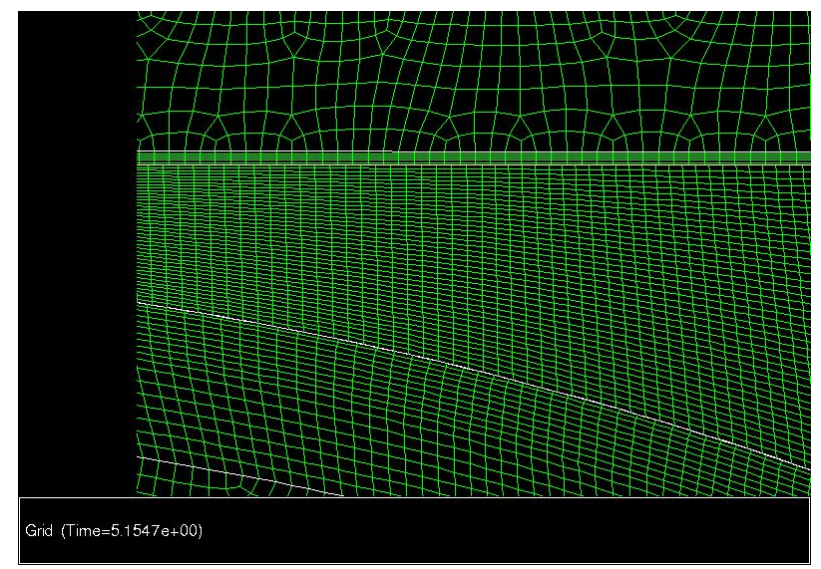

(e) Appendix Gap Close

Figure 12. Hot End Grid Strategy 


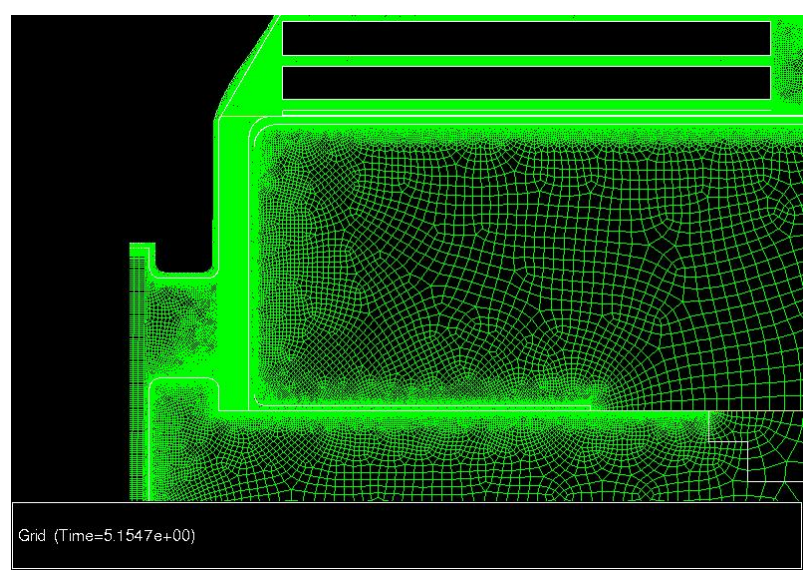

(a) Top and Bottom Seal, Rod, Compression Space

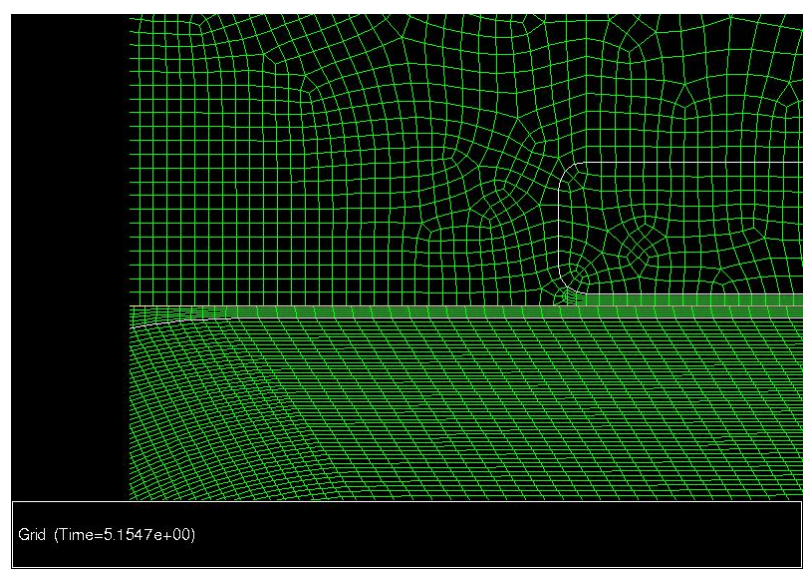

(c) Top Seal Close-up

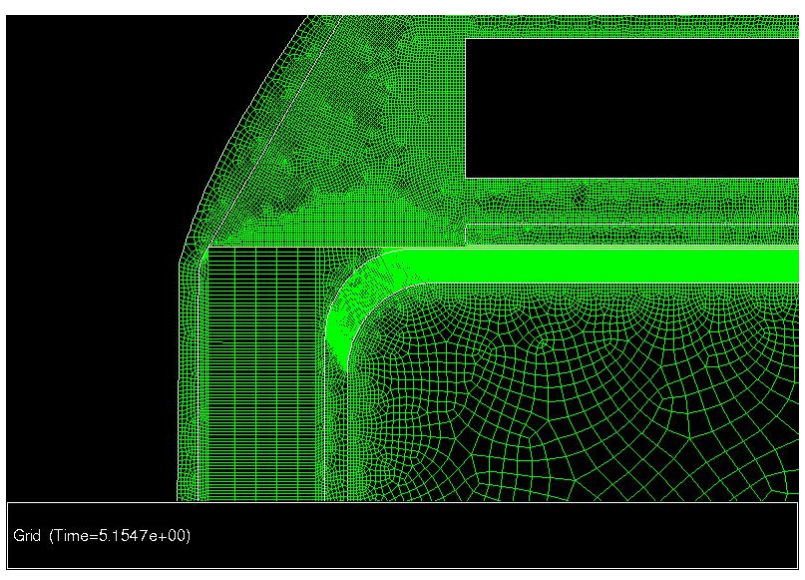

(b) Top Seal and Compression

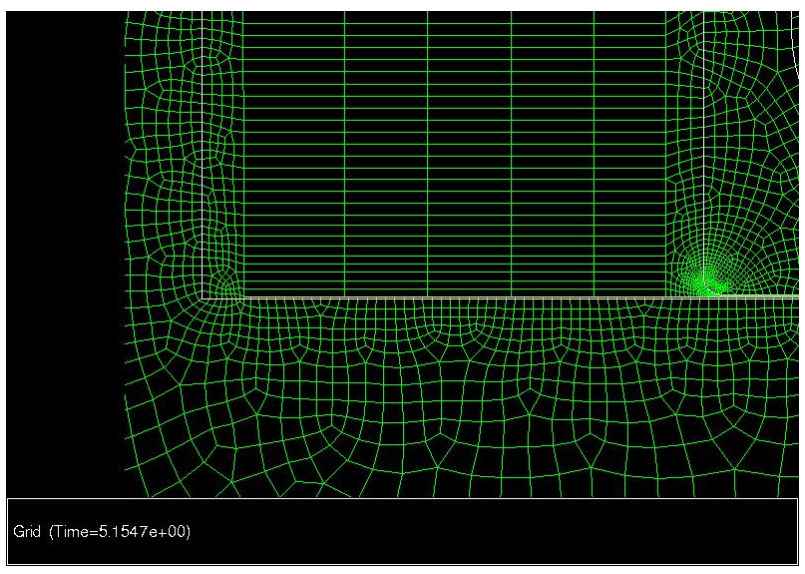

(d) Bottom Seal and Compression

Figure 13. Seal Grid Strategy 


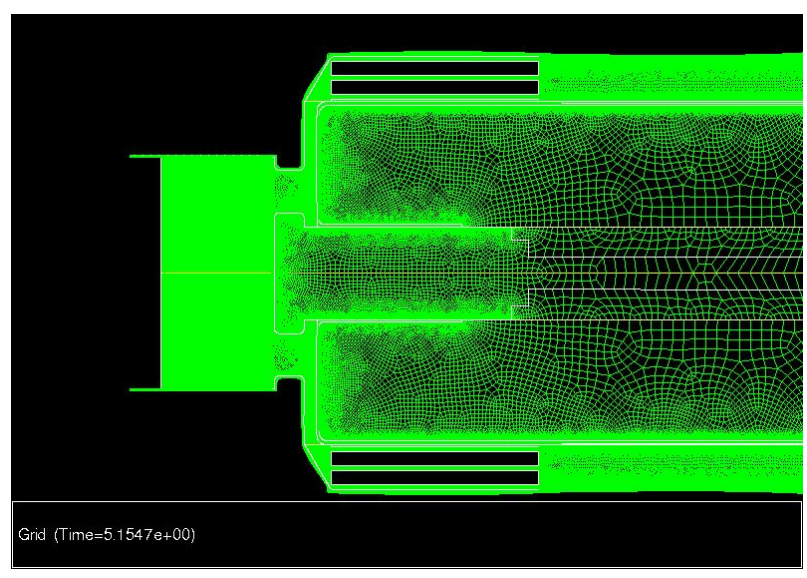

(a) Left Half

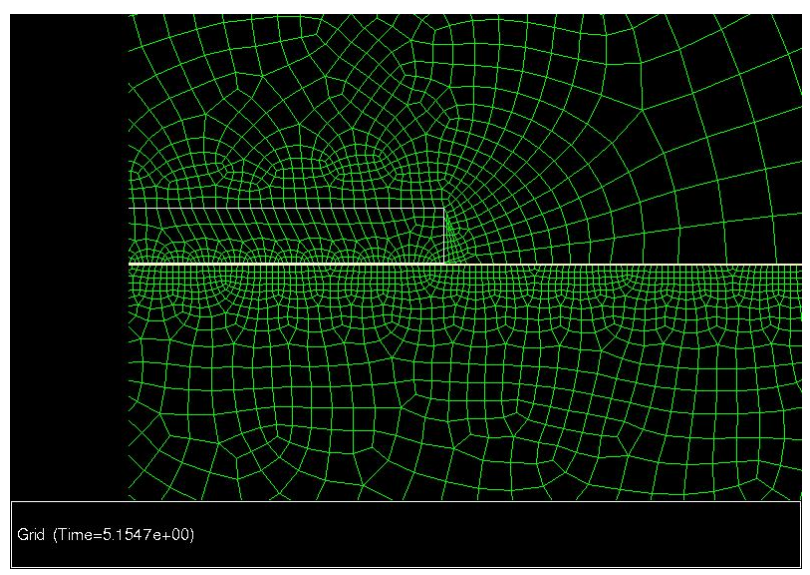

(c) Inside Seal Close-up

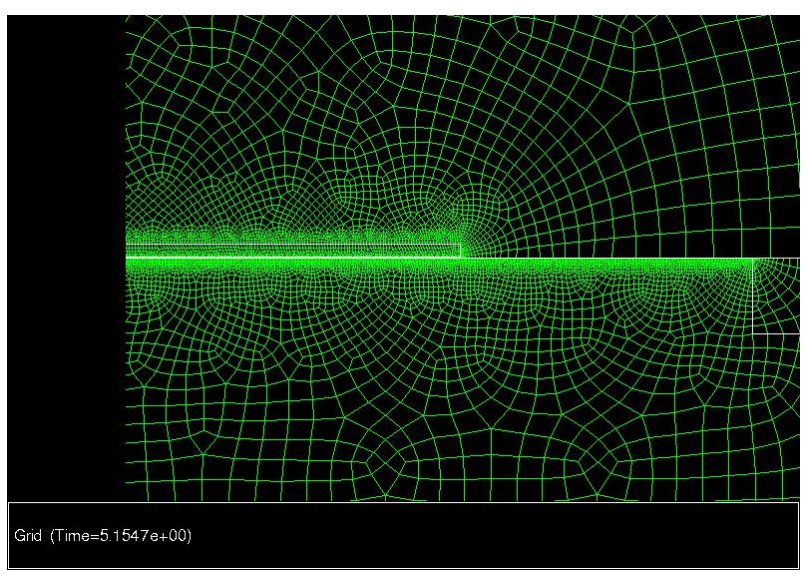

(b) Inside Seal

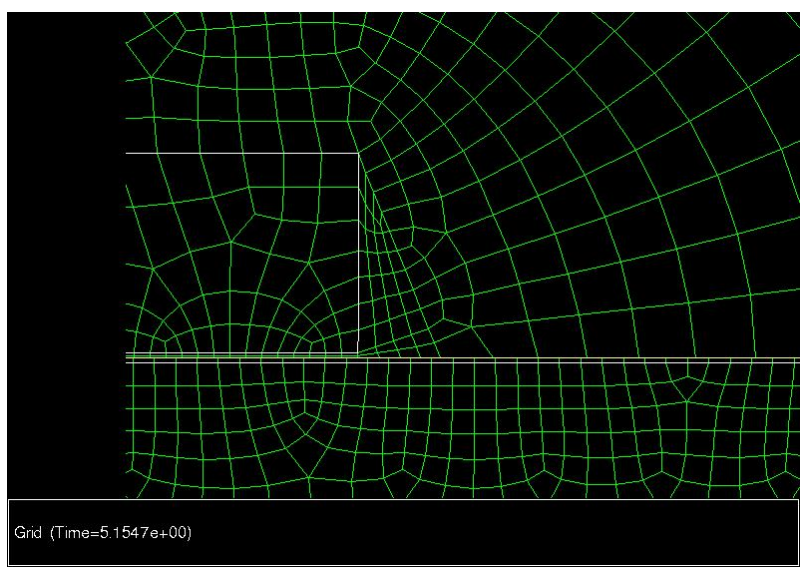

(d) Inside Seal Close-up2

Figure 14. Inner Seal Grid Strategy 


\section{Solver Optimization}

While one's choices are limited with commercial codes, they do offer a variety of low-order solvers to choose from, including low Mach number variable density flows. ${ }^{115}$ A comparison of two commercial codes with the latest high-order numerical techniques demonstrates some of the differences a solver decision can make. ${ }^{50}$ One of the limitations currently in Fluent is only first order accuracy is available in time when the mesh moves. CFD-ACE permits a higher accuracy in time with moving meshes, but does not have a coupled solver. The results shown in the next section utilize the segregrated implicit solver in Fluent, although it was later discovered the coupled implicit solver is potentially significantly better. Of course, the grid used for the segregrated solver may need further improvement if a coupled solver is used. It was found that the best method in Fluent and the best method in CFD-ACE performed comparably on simpler heat transfer test

problems. ${ }^{50}$ And with sufficient grid quality and density, the answers are comparable to the latest numerical methods.

One of the challenges to utilizing actual engine geometry is the difficulty of creating a high quality mesh as discussed previously. However, certain switches in the solvers may be adjusted to attempt to compensate for poor grid quality in regions of conjugate heat transfer. ${ }^{116}$ In what follows are specific recommendations for improving conjugate heat transfer and they contain Fluent specific switches. The other commercial packages should be modified with their own specific format.

First, skewed meshes require secondary temperature gradients to be turned off to improve stability and to reduce undershoot/overshoot of local cell temperatures. In Fluent, this is accomplished by the command, "(rpsetvar 'temperature/secondary-gradient? \#f)"

Second, in conjugate heat transfer problems with vastly different thermal conductivities between the fluid and solid zones, cells near the interface can experience round-off errors. To mitigate this effect, we want to ensure that the coarse levels of the AMG are visited. It is recommended that the default AMG cycle for energy be changed from Flexible to either F, V, or W-cycle. The F and V-cycles are more efficient in parallel simulations. The termination criteria should also be reduced to either 0.01 or 0.001 in order to tighten up convergence.

Third, although a reasonable temperature distribution can be achieved using single precision, in order to ensure that the total heat transfer is balanced the use of double precision is recommended.

Fourth, if convergence still remains problematic with secondary gradients turned off, it is recommended that explicit under-relaxation of temperature be used to stabilize the solution. When this is activated, the energy equation is solved with a URF of 1 , but the solution is explicitly relaxed with respect to the previous iteration. This allows for the equations to be efficiently solvered (URF equal 1) and instabilities due to poor quality mesh and non-linear material properties to be mitigated (relaxation factor). The GUI entry of URF for energy will specify the explicit relaxation factor to be used. To active this, the scheme command is: (rpsetvar 'temperature/explicit-relax? \#t) 


\section{Comparison with Analytical and Experimental Data}

The approach just described was applied to simulating a Stirling engine built by Infinia Corp. ${ }^{117}$ (formerly Stirling Technology Company) being considered for use in space missions. The engine is currently being tested for long-duration missions and hence a good deal of experimental performance information is available for comparison. The geometry is export controlled for these engines and so limited information may be shared with the public. The entire simulation was performed first, with no knowledge of the "correct" answer either from experiment or calibrated one-dimensional analysis. The operating conditions used in the simulation are shown below (Table 1):.

\begin{tabular}{lc}
\hline \hline Hot-End Temperature, $\mathrm{K}$ & 923 \\
Cold-End Temperature, $\mathrm{K}$ & 353 \\
Ambient Temperature, K & 293 \\
Frequency, Hz & 80 \\
Mean Pressure, Pa & $2.429 \mathrm{E}+6$ \\
Power Piston Amplitude, mm & $6.0 \mathrm{e}-3$ \\
\hline \hline
\end{tabular}

Table 1. Operating Conditions

The pressures and heat transfer occuring in various parts of the engine over two cycles are shown in Fig. 15(a). The pressure in the left (cooler end), middle, and right (heater end) of the regenerator is shown in Fig. 15(b). The average pressure in the expansion and compression spaces are shown to be about equal in Fig. 15(c). And, the temperature after 412.376 cycles of simulation are shown in Fig. 16 for an instant in time (135.36 degree Crank angle with reference to 0 degree displacer located at mean position) in the cold end of the machine and for the hot end are shown in Fig. 17. Notice the effects of radial heat transfer on the regenerator.

An initial comparison with Sage suggested the axisymmetric simulation was over-predicting the indicated power as shown in Table 2. And the overall heat transfer in and out fell within a band predicted by Sage in which heat loss to the environment was included and then assumed excluded (adiabatic).

\begin{tabular}{lccc}
\hline \hline & $\begin{array}{c}\text { Axisymmetric } \\
\text { Simulation }\end{array}$ & $\begin{array}{c}\text { Modified Skupinski Sage 1D } \\
\text { With Ambient Heat Loss }\end{array}$ & $\begin{array}{c}\text { Modified Skupinski Sage 1D } \\
\text { No Ambient Heat Loss }\end{array}$ \\
\hline PV Power, W & 79.65 & 68.77 & 70.14 \\
Heat In, W & 247.315 & 260.94 & 193.8 \\
Heat Out, W & 168.313 & 191.9 & 123.7 \\
PV Efficiency & .322 & .264 & 0.362 \\
Pressure Ratio & 1.209 & 1.187 & 1.187 \\
Regenerator Delta Press., Pa & 10466.3 & 15,888 & 15790 \\
Heater Delta Press., Pa & 682 & 194 & 192 \\
Cooler Delta Press., Pa & 896 & 316 & 315 \\
Pressure Amplitude., Pa & 225269 & 203100 & 203200 \\
Mean Pressure, Pa & 2429130 & 2378000 & 2378000 \\
\hline \hline
\end{tabular}

Table 2. Comparison With Sage 1D Results 


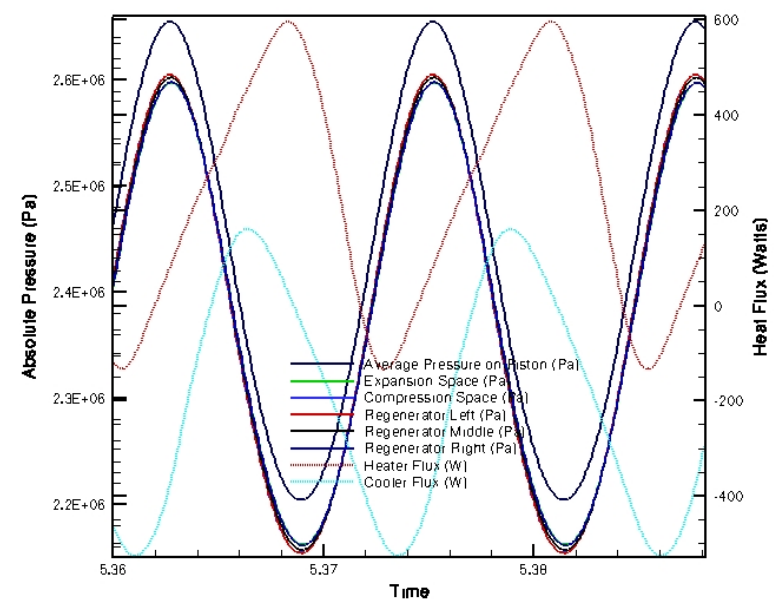

(a) Pressure and Heat Transfer over Two Cycles

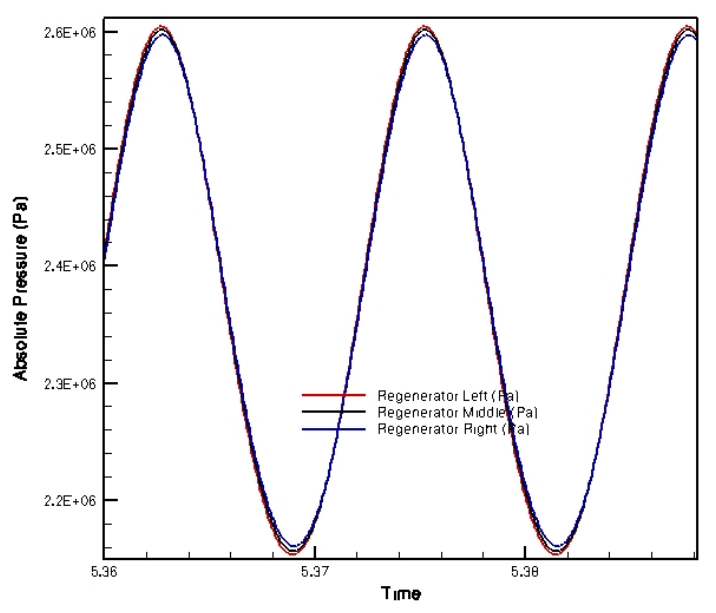

(b) Pressure Along Regenerator over Two Cycles

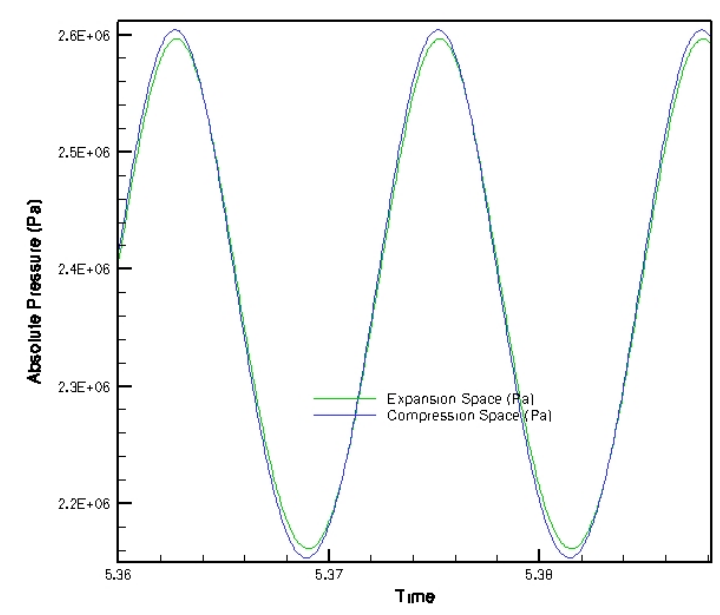

(c) Comparison of Expansion and Compression Pressure

Figure 15. Pressure and Heat Transfer over Two Cycles 


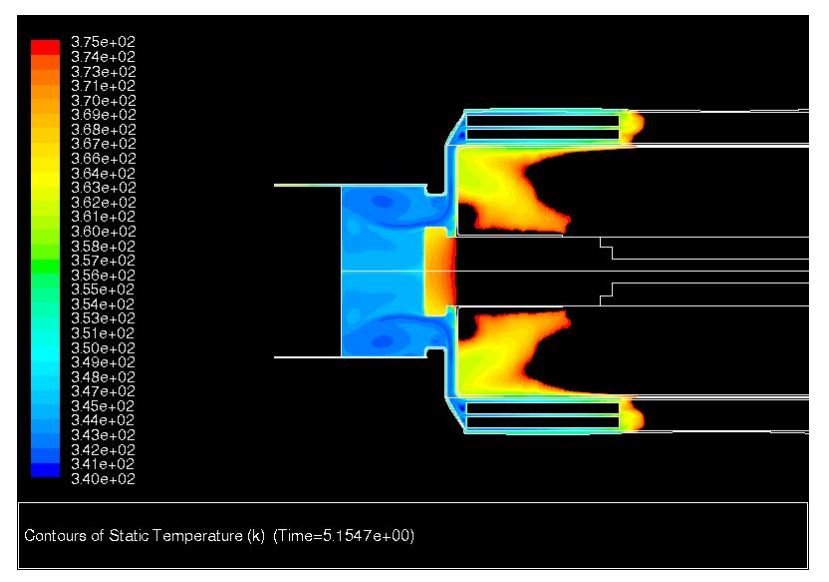

(a) Left Half

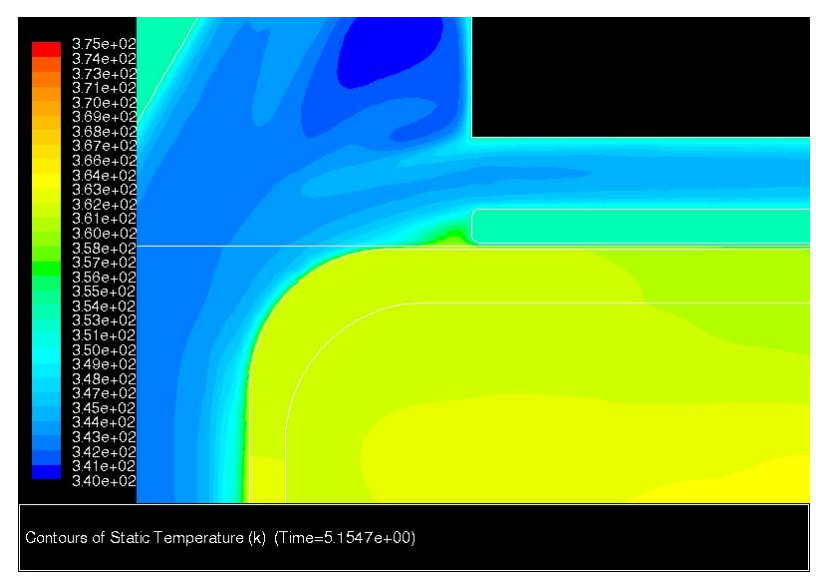

(c) Cooler and Seal

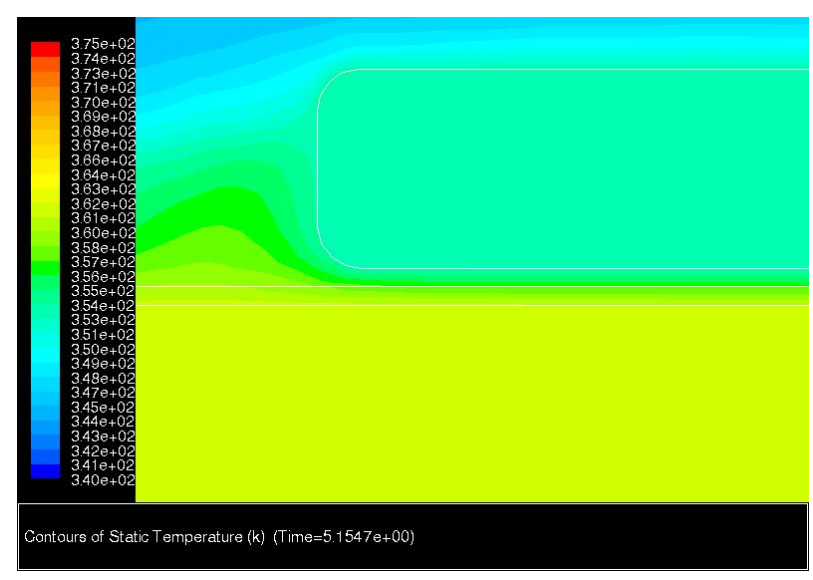

(e) Seal Pretty Close

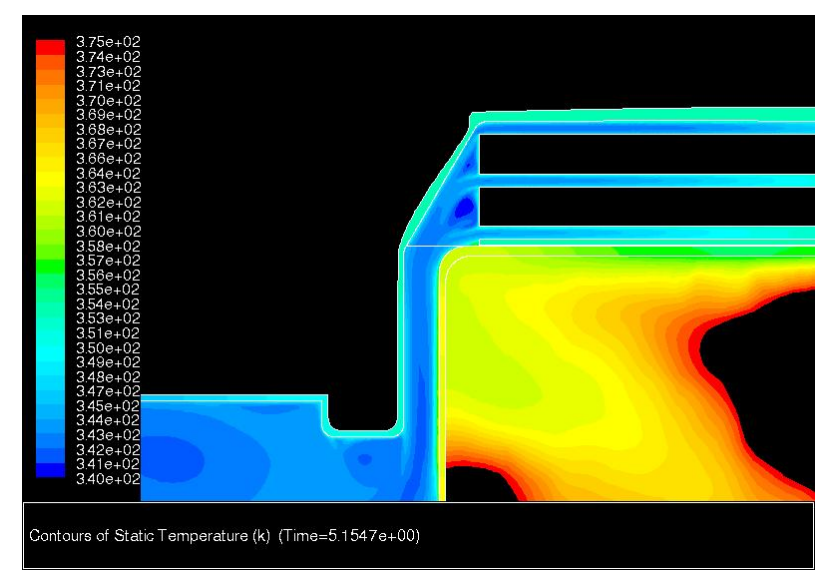

(b) Compression and Cooler

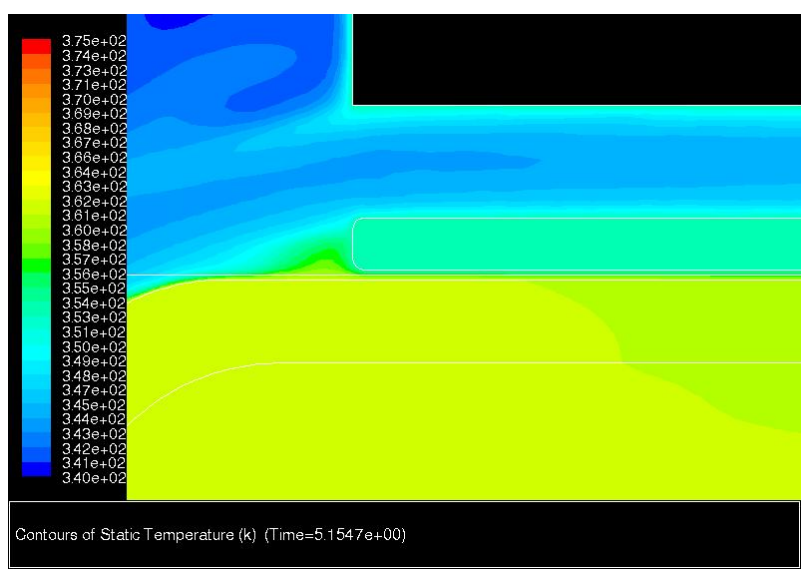

(d) Seal Region

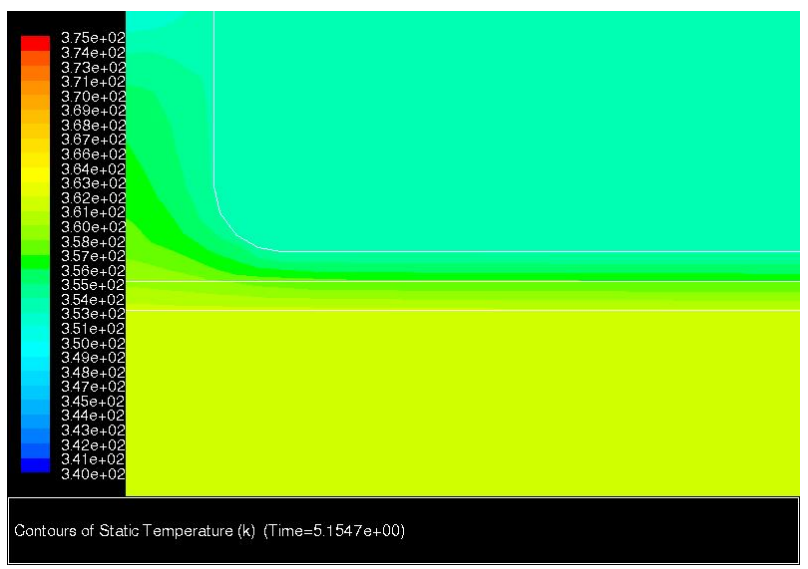

(f) Seal Very Close

Figure 16. Cold End Temperature 


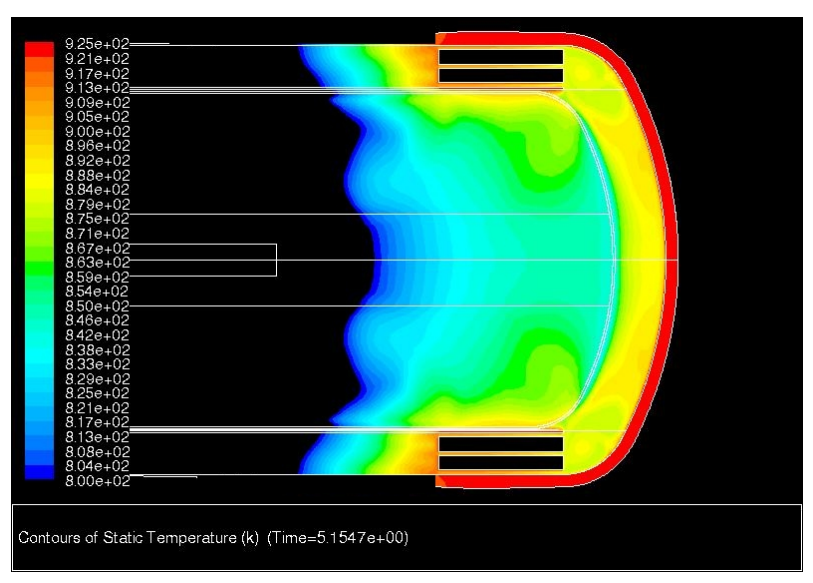

(a) Right Half

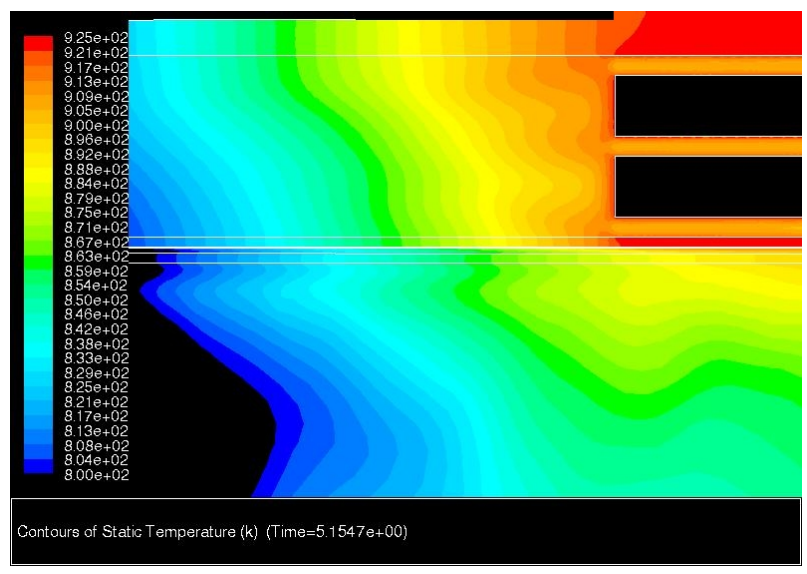

(c) Around Heater

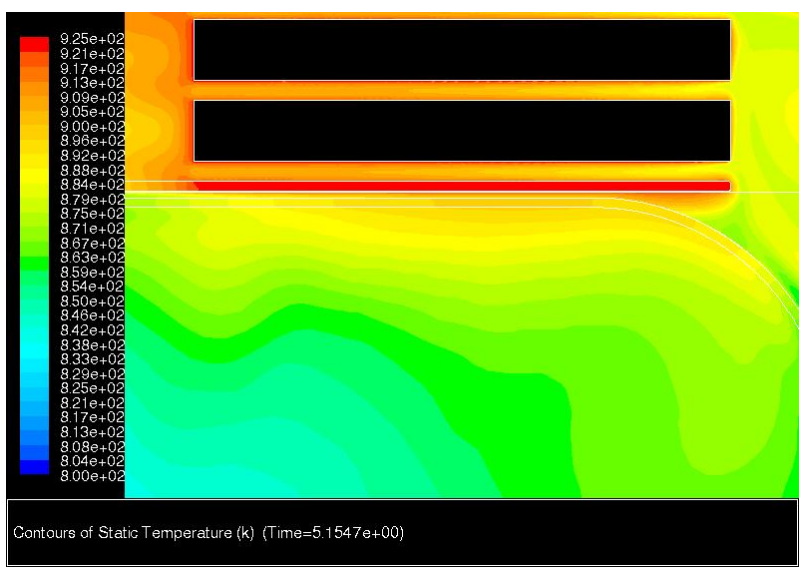

(b) Below Heater

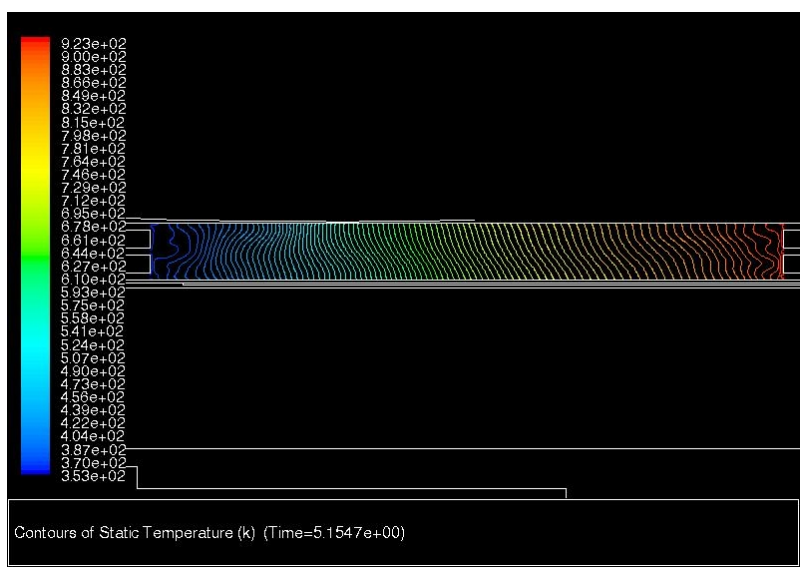

(d) Regenerator

Figure 17. Hot End and Regenerator Temperature 
But then we gathered the actual performance of two identical engines identified as Technology Demonstrator Convertor (TDC) \#13 and \#14 from over many thousands of hours of operation since August 2003. As shown in Table 3, the axisymmetric solution which assumed no ambient heat loss to the environment, predicted not only the higher indicated power more accurately, but the efficiency was essentially within the variability of each built machine.

A few words of caution about this encouraging result are in order. First, due to experimental limitations the piston amplitude is not known for certain. The original designs call for a piston amplitude of $6+/-.08 \mathrm{~mm}$. And the mean operating pressure is $2.517 \mathrm{Mpa}$ compared to the simulated mean pressure of 2.42913 Mpa. If the piston amplitude in the experiment is exactly $6.00 \mathrm{~mm}$, then this mean pressure difference implies the simulated power would need to be corrected up to $82.5874 \mathrm{~W}$. But since the engines are tuned for maximum performance and the energy measurements are considered more reliable than the piston amplitudes, it seems appropriate to conclude this simulation did in fact predict the performance and efficiency within the bounds of variability of the two engines tested. Since a slightly lower piston amplitude would counter-balance the corrected higher power just shown, it is important to improve the experimentally derived piston amplitude for future comparisons.

\begin{tabular}{lccc||ccc}
\hline \hline & $T_{h}$ & $T_{c}$ & freq & net Qin & PV Pout & net Qout \\
\hline TDC \#13 & 646.0 & 92.4 & 81.4 & 242.1 & 78.2 & 163.9 \\
TDC \#14 & 646.5 & 94.4 & 81.4 & 250.4 & 79.6 & 170.8 \\
\hline \hline Simulation & 650.0 & 80.0 & 80.0 & 247.3 & 79.7 & 168.3 \\
\hline \hline \%Err-AVE & $100.6 \%$ & $100.3 \%$ & $98.2 \%$ & $100.4 \%$ & $100.9 \%$ & $100.6 \%$ \\
\%Err-TDC\#13 & $100.5 \%$ & $100.2 \%$ & $98.2 \%$ & $102.1 \%$ & $101.9 \%$ & $102.7 \%$ \\
\%Err-TDC\#14 & $100.6 \%$ & $100.3 \%$ & $98.2 \%$ & $98.8 \%$ & $100.0 \%$ & $98.5 \%$ \\
\hline \hline
\end{tabular}

Table 3. Comparison With Experimental Results

\section{Conclusion}

For the first time in the U.S., a fully converged axisymmetric simulation of an actual Stirling engine was successfully performed. And moreover, by utilizing the latest advances in computer processors, communication hardware, parallel decomposition strategy, dynamic meshing, solution algorithms, and careful grid design, it is possible to compute one complete Stirling cycle in less than an hour.

While not conclusive until additional testing is completed, the full axisymmetric simulation predicted the engine performance within the bounds of both engine test's data. And predicted the overall efficiency and indicated power considerably better than our initial efforts with using a leading one-dimensional Stirling analysis prediction on the first attempt. The one-dimensional analysis can certainly be improved by modifying various friction and heat transfer factors, either from experimental data or from this axisymmetric solution. But the real value of the axisymmetric solution is no adjustments were required because the engine is simulated from first principles. Of course the one-dimensional analysis is valuable for other reasons such as fast optimizations and performance mapping.

These results and observations lead to the conclusion that one, two, and three-dimensional modeling should all be employed and all three paradigms provide important capabilities that when combined provide

potent combination of initial design, empirical coefficient adjustment, optimization, and final prototype demonstration before the first metal is cut. 


\section{References}

${ }^{1}$ Beale, W.T.:" Free Piston Stirling Engines - Some Model Tests and Simulations", [Preliminary investigation of free-piston Stirling engines.], SAE International Automtive Engineering Conference, Jan. 1969 2000

${ }^{2}$ Geng, S.M. : "A 3-D magnetic analysis of a linear alternator for a Stirling power system.", NASA/TM-2000-210249, 2001

${ }^{3}$ Geng, S.M. : "A 3-D magnetic analysis of a Stirling convertor linear alternator under load", NASA/TM-2001-211084,

${ }^{4}$ Chua, C.K. : "Rapid prototyping: principles and applications", World Scientific, 2003, 420p.

${ }^{5}$ Gedeon, D. : "Sage - Object-oriented software for Stirling machine design", AIAA Paper 94-4106. 1994

${ }^{6}$ Gedeon, D. : "Manifest: A Computer Program for 2-D Flow Modeling in Stirling Machines", NASA CR-182290, 1989

${ }^{7}$ Gedeon, D. : "Sage:Stirling-Cycle Model-Class Reference Guide, Third Ed.", Gedeon Assocatiates, 1999

${ }^{8}$ Gedeon, D. : "Sage:User's Guide, Third Edition" Gedeon Assocatiates, 1999

${ }^{9}$ Gedeon, D. : "GLIMPS Version 4: User's Manual", Gedeon Associates, July 1992.

${ }^{10}$ Bauwens, L., "Consistency, Stability, Convergence of Stirling Engine Models", Mitch/Stirling Machines/Systems, Inc. Berkeley, CA 94710, Dept. Mech. Engineering, Univ. of Calif. at Berkeley, Berkely, CA 94720

${ }^{11}$ Mitchell, M. P. : "Modelling Pulse Tube Coolers with the MS*2 Stirling Cycle Code, 10th Int. Cryocooler Conference, Monterey, 1998.

${ }^{12}$ http://www.bell.mma.edu/ jmcent/laser.html, "LASER - Linear Analysis of Stirling Cycle Engines and Refrigerators".

${ }^{13}$ Ward, B., Swift, G. "DeltaE- Design Environment for Low-Amplitude ThermoAcoustic Engines" LA-CC-93-8, Feb. 1996, June, 2001

14"ARCOPTR : Ames Research Center Orifice Pulse Tube Refrigerator", http://arcoptr.arc.nasa.gov/ARCOPTRoptions.html, 2003

${ }^{15}$ Kuriyama, T. (Japan) Lewis, M. A. Radebaugh, R. Xiao, J. H. (PHYSICAL AND CHEMICAL PROPERTIES DIVISION - 838) Effect of Regenerator Geometry on Pulse Tube Refrigerator Performance Advances in Cryogenic Engineering, July, 1997 , Portland, OR - June 01, 1998

${ }^{16}$ Schock, A. : "Stirling Engine Nodal Analysis Program", J. Energy, Vol. 2, No. 6, 1978

${ }^{17}$ Swift, G.W., Ward, W.C. : "Simple Harmonic Analysis of Regenerators", J. of Thermophysics and Heat Transfer, Vol. 10, No. 4, Oct.-Dec. 1996

${ }^{18}$ Lu, G.Q., Cheng, P. : " Numerical and experimental study of a Gifford-McMahon-type pulse tube refrigerator" JOURNAL OF THERMOPHYSICS AND HEAT TRANSFER 17 (4): 457-463 OCT-DEC 2003

${ }^{19}$ Regan, T.F., Lewandowski, E.J.: "Application of the GRC stirling convertor system dynamic model : final report" NASA-CR-213364, 2004

${ }^{20}$ Regan, T.F.: "Free-Piston Stirling Convertor Simulation Model Includes Case Motion", AIAA-2003-5931, Aug. 2003

21: Regan, T.F., Gerber, S.S., Roth, M.E. : "Development of a Dynamic, End-to-End Free Piston Stirling Convertor Model", NASA/TM-2004-212941

${ }^{22}$ Lewandowski, E.J., Regan, T. : "Overview of the GRC Stirling Convertor System Dynamic Model", AIAA-2004-5671, Aug. 2004

${ }^{23}$ Ulusoy, N. : "Dynamic Analysis of Free-Piston Stirling Engines", Ph.D. Thesis, Case Western Reserve University, 1994.

${ }^{24}$ Benvenuto, G., Monte, F. de : "Analysis of Free-Piston Stirling Engine/Linear Alternator Systems Part 2: Results", J. of Prop. and Power, Vol. 11, No. 5, Sept.-Oct. 1995

25: Qui, S., Peterson, A.A. : "Linear Dynamic Modeling and Numerical Simulation of an STC Stirling Convertor", 1st Int. Energy Conv. Eng. Conf., Aug. 2003

${ }^{26}$ Dyson, R.W., Wilson, S.D., Tew, R.C.: "Review of Computational Stirling Analysis Methods", Second IECEC, Providence, RI, Aug. 2005

${ }^{27}$ Gedeon, D. : "Computational Techniques for the two-dimensional Gasdynamic Equations in Stirling Engine Regenerators and Associated Manifolds", 1985.

${ }^{28}$ Gedeon, D. : "Developments in two-dimensional regenerator modeling", 23rd IECEC, 1988, Vol. 1, pp39-44.

${ }^{29}$ Ibrahim, M.B., "Development of Multi-Dimensional Stirling Engine Code", August Progress Report on NASA Grant NAG 3-955., 1993.

${ }^{30}$ Hall, C.A., Porshing, T.A., Medley, J, Tew, R.C. : "Multidimensional computer simulation of Stirling cycle engines", 25th IECEC, 1990, Vol. 5, pp. 407-411

${ }^{31}$ Ibrahim, M.B., Mittal, M., Simon, T., and Gedeon, D., "A 2-D CFD model of a Free Piston Stirling Engine for Space Applications with Annular Heat Exchangers", AIAA 2nd Int. Energy Conversion Engineering Conference, Providence, RI, Aug. 16-19, 2004. AIAA-2004-5583.

${ }^{32}$ Tew, R.C., Ibrahim, M.B. : "Two-dimensional Compressible Non-Acoustic Modeling of Stirling Machine-Type Components", J. of Prop. and Power, Vol. 19, No. 5, Sept.-Oct. 2003

${ }^{33}$ Zhang, Z., "2D Numerical Model of Flow and Heat Transfer for Stirling Engine Components", Doctoral Dissertation, Cleveland State University, May 2003. 


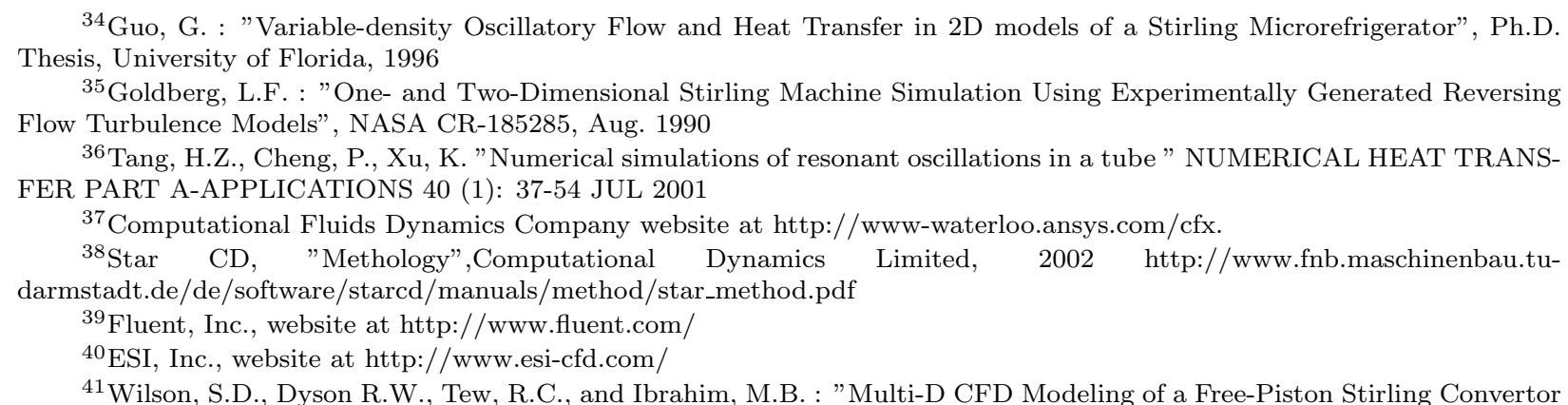
at NASA GRC", AIAA 2nd Int. Energy Conversion Engineering Conference, Providence, RI, Aug. 16-19, 2004, AIAA-2004-5573

${ }^{42}$ Makhkamov, K., Ingham, D.B. : "Theoretical Investigations on the Stirling Engine Working Process", A00-37715, AIAA-2000-2815, 2000

${ }^{43}$ Makhkamov, K., Djumanov, D. : "Three-dimensional CFD modeling of a Stirling engine", ST_TA1_15, 11th Int. Stirling Engine Conf., Rome, Italy, Nov. 2003

${ }^{44}$ Mahkamov, K., Djumanov, D., Orunov, B., Korobkov, A. : "A $\gamma$ - Type Stirling Engine: Some Results of Second-Order Numerical Simulations and Experimentals Tests", 1st Int. Energy Conversion Eng. Conf., AIAA 2003-5933, Aug. 2003

${ }^{45}$ Zhang, Z., and Ibrahim, M. "Development of CFD Model for Stirling Engine and its Components", AIAA 2nd IECEC, Providence, RI, August 16-19, 2004. AIAA-2004-5674

${ }^{46}$ Dyson, R.W., Wilson, S.D., Tew, R.C., Demko, R. : "On the Need for Multidimensional Analysis", Third IECEC, San Francisco, Aug. 2005

${ }^{47}$ Tew, R.C., Cairelli, J.E., Ibrahim, M., Simon, T.W., Gedeon, D.: "Overview of NASA Multi-Dimensional Stirling Convertor Code Development and Validation Effort", NASA/TM-2002-211997, Dec. 2002.

${ }^{48}$ Hirata, K., Kagawa, N., Takeuchi, M., Yamashita, I., Isshiki, N., Hamaguchi, K. : "Test Results of Applicative 100 W Stirling Engine", 96204.

${ }^{49}$ Ibrahim, M.B., Tew, R.C., Zhang, Z., Gedeon, D. Simon, T. : "CFD Modeling of Free-Piston Stirling Engines", NASA/TM-2001-211132, IECEC2001-CT-38, Sept. 2001

${ }^{50}$ Dyson, R.W., Wilson, S.D., Tew, R.C., Demko, R. : "Stirling Analysis Comparison of Commercial vs. High-Order Methods", Third IECEC, San Francisco, Aug. 2005

${ }^{51}$ Zuijlen, A., Bijl, H. : "Implicit and explicit higher order time integration schemes for structural dynamics and fluidstructure interaction computations", Comp. and Structures, 83, pp. 93-105, 2005

${ }^{52}$ Tsitouras, Ch., Simos, T.E. : "Optimized Runge-Kutta pairs for problems with oscillating solutions", J. Comp. and Applied Math., 147, pp. 397-409, 2002.

${ }^{53}$ Franco, J.M. : "Runge-Kutta methods adapted to the numerical integration of oscillatory problems", Applied Num. Math., 50, pp. 427-443, 2004

${ }^{54}$ Iserles, A. : "Think globally, act locally: Solving highly-oscillatory ordinary differential equations", Applied Num. Math., 43, pp. 145-160, 2002.

${ }^{55}$ Tsitouras, C. : "A High-Order Explicit Runge-Kutta Pair for Initial Value Problems with Oscillating Solutions", Computers and Mathematics with Applications, 37, pp. 31-36, 1999.

${ }^{56}$ Franco, J.M. : "Runge-Kutta-Nystrom methods adapted to the numerical integration of perturbed oscillators", Comp. Phys. Comm., 147, pp. 770-787, 2002.

${ }^{57}$ Calvo, M., Franco, J.M., Montijano, J.I., Randez, L. "Explicit Runge-Kutta methods for initial value problems with oscillating solutions", J. Comp. and Applied Mathematics, 76, pp. 195-212, 1996.

${ }^{58}$ Thieme, L.G.; Schreiber, J.G. : "NASA GRC Stirling Technology Development Overview", NASA/TM-2003-212454, Aug. 2003

${ }^{59}$ Thieme, L.G., Schreiber, J.G., Mason, L.S. : "Stirling Technology Development at NASA GRC", NASA/TM-2001211315/REV1, Jan. 2002

${ }^{60}$ Schreiber, J. : "Tutorial on Free-Piston Stirling Power Conversion Technology (How Does it Work?), Space Technology and Applications International Forum, Feb. 2001

${ }^{61}$ Schreiber, J.G., Thieme, L.G., Mason, L.S.: "Status of Free-piston Stirling Power Conversion in the United States Space Program", 10th International Stirling Engine Conference, Osnabruk, Germany, Sept. 2001.

${ }^{62}$ Furlong, R., Shaltens, R. : "Technology Assessment of DOE's 55-We Stirling Technology Demonstrator Convertor (TDC)", NASA/TM-2000-210509, Oct. 2000

${ }^{63}$ Abelson, R.D., Balint, T.S., Coste, K., Elliott, J.O.,Randolph, J.E., Schmidt, G.R., Schriener, T., Shirley, J.H., Spilker, T.R.: "Expanding Frontiers with Standard Radioisotope Power Systems", JPL D-28902, PP-266 0332, Jan. 12, 2005

${ }^{64}$ Tew, R., Ibrahim, M., Simon, T., Mantell, S., Gedeon, D., Qui, S., Wood, G.: "Overview 2003 of NASA Multi-D Stirling Convertor Code Development and DOE \& NASA Stirling Regenerator R \& D Efforts", NASA TM-2004-212908, Space Technology Applications Int. Forum 2004. 


\footnotetext{
${ }^{65}$ Tew, R., Dyson, R.W., Wilson, S.D., Demko, R. "Overview 2004 of NASA-Stirling Convertor CFD Model Development and Regenerator R \& D Efforts", STAIF 2005, Albuquerque, NM, Feb. 16-17

${ }^{66}$ Tew, R.C., Thieme, L.G., Dudenhoefer, J.E. : "Recent Stirling Engine Loss-Understanding Results", 25th IECEC, NASA TM 103122, 1990

${ }^{67}$ Kaviany, M. : "Performance of a Heat Exchanger Based on Enhanced Heat Diffusion in Fluids by Oscillation: Analysis", J. of Heat Transfer, Vol. 112 (49), Feb. 1990

${ }^{68}$ Kurzweg, U.H. : "Enhanced heat conduction in oscillating viscous flow within parallel-plate channels", J. Fluid Mech., Vol. 156, 1985, pp. 291-300

${ }^{69}$ Peric, M., Scheuerer, G.: "CAST - A Finite Volume Method for Predicting Two-dimensional Flow and Heat Transfer Phenomena", GRS-Technische Notiz, SSR-89-01, Sept. 1989.

${ }^{70}$ Patankar, S.V., Spalding, D.B. : "A Calculation Procedure for Heat, Mass, and Momentum Transfer in ThreeDimensional Parabolic Flows", Int. J. Heat Mass Transfer, Vol. 15, p. 1787, 1972

${ }^{71}$ Ibrahim, M., Tew, R.C. Dudenhoefer, J.G., "Two dimensionsal numerical simulation of a Stirling engine heat exchanger", 24th IECEC, 1989, Vol.6, pp2795-2802.

${ }^{72}$ Ibrahim, M., Tew, R.C., Dudenhoefer, J.G., "Further two-dimensional code development for Stirling space engine components", 25th IECEC, 1990, Vol. 6, pp. 329-335.

${ }^{73}$ Ibrahim, M., Kannapareddy, M. : "Computational Heat Transfer Analysis for Oscillatory Channel Flows", NASA-CR199238,1992

${ }^{74}$ Guo, G., Kurzweg, U.H. : "2D Numerical Simulation of Heat Transfer in a Stirling Microrefrigerator Model", AIAA Paper 96-1807, 31st AIAA Thermophysics Conference, New Orleans, LA, June, 1996

${ }^{75}$ Ibrahim, M.B., Mittal, M., Jiang, N., Simon, T. : "Validation of Multi-Dimensional Stirling Engine Codes: Modeling of the Heater Head", IECEC, San Francisco, Aug. 2005

${ }^{76}$ Qui, S. "Preliminary Computational Fluid Dynamics Modeling of STC Stirling Engines", IECEC, Providence, Rhode Island, Aug. 2004

${ }^{77}$ Flake, B., Razani A., "Modeling Pulse Tube Cryocoolers With CFD", 2004

${ }^{78}$ Flake, B. Razani, A., "Phase Shift and Compressible Fluid Dynamics in Inertance Tubes", 2004

${ }^{79}$ Cha, J. "CFD Simulation of Multi-Dimensional Effects in Inertance Tube Pulse Tube Cryocoolers", Master's thesis, Georgia Inst. of Tech., May, 2004

${ }^{80}$ Yuan, Z.S. : "Oscillatory Flow and Heat Transfer in a Stirling Engine Regenerator", Case Western Reserve University, Ph.D. Thesis, 1992.

${ }^{81}$ Harvey, J.P. "Oscillatory Compressible Flow and Heat Transfer in Porous Media - Application to Cryocooler Regenerators", Doctoral Dissertation, Georgia Inst. of Tech., Dec. 2003

${ }^{82}$ Wang, C., Wu, P.Y., Chen, Z.Q. : "NUMERICAL MODELING OF AN ORIFICE PULSE TUBE REFRIGERATOR" CRYOGENICS 32 (9): 785-790 1992

${ }^{83}$ Wang C "Numerical analysis of 4K pulse tube coolers .1. Numerical simulation " CRYOGENICS 37 (4): $207-213$ APR 1997

${ }^{84} \mathrm{Ju}$ Y.L., Wang C., Zhou Y. "Numerical simulation and experimental verification of the oscillating flow in pulse tube refrigerator", CRYOGENICS 38 (2): 169-176 FEB 1998

${ }^{85}$ Alexeev A, Gutfinger C "Resonance gas oscillations in closed tubes: Numerical study and experiments ", PHYSICS OF FLUIDS 15 (11): 3397-3408 NOV 2003

${ }^{86}$ Zhang X.J., Liu H.X., Wang R.Z., Shi F. "Numerical simulation of heat transfer in regenerator of solid adsorption refrigeration system" RENEWABLE ENERGY 26 (4): 599-610 AUG 2002

${ }^{87}$ Zhu S.W., Matsubara Y. "A numerical method of regenerator ", CRYOGENICS 44 (2): 131-140 FEB 2004

${ }^{88}$ Ataer O.E. "Numerical analysis of regenerators of free-piston type Stirling engines using Lagrangian formulation ", INTERNATIONAL JOURNAL OF REFRIGERATION-REVUE INTERNATIONALE DU FROID 25 (5): $640-652$ AUG 2002

${ }^{89}$ Zhang, Z. Posted on the web at http://www.cfdreview.com/jobs.pl?op=view_res\&rid=264, No specific details since proprietary, 2003

${ }^{90}$ Noh D.S., Hong S.K., Ryou H.S., Lee S.H. " An experimental and numerical study on thermal performance of a regenerator system with ceramic honeycomb ", KSME INTERNATIONAL JOURNAL 15 (3): 357-365 MAR 2001

${ }^{91}$ Bauwens, L., "Entropy Balance and Performance Characterization of the Narrow Basic Pulse-Tube Refrigerator", AIAA97-0814, 1997

${ }^{92}$ Bauwens, L., "Oscillating Flow of a Heat-Conducting Fluid in a Narrow Tube", J. Fluid Mechanics, Vol. 324, 1996, pp. $135-161$

${ }^{93}$ Gedeon, D., Tew, R. : Personal Communication, 2004

${ }^{94}$ Ibrahim, M., Rong, W., Simon, T., Gedeon, D. : "Simulations of Flow and Heat Transfer Inside Regenerators Made of Stacked Welded Screens Using Periodic Cell Structures", 2nd IECEC, Aug. 2004

${ }^{95}$ Ibrahim, M.B., Rong, W., Simon, T.W., Tew, R., Gedeon, D. "Microscopic Modeling of Unsteady Convective Heat Transfer in a Stirling Regenerator Matrix", 1st IECEC, 2003
} 
${ }^{96}$ Howse J.W., Hansen G.A., Cagliostro D.J., Muske K.R. "Solving a thermal regenerator model using implicit NewtonKrylov methods", NUMERICAL HEAT TRANSFER PART A-APPLICATIONS 38 (1): 23-44 JUL 2000

${ }^{97}$ Nakayama, A., Kuwahara, F. : "Numerical Modeling of Convective Heat Transfer in Porous Media Using Microscopic Structures", Handbook of Porous Media

${ }^{98}$ Bastian, P. : "Higher Order Discontinuous Galerkin Methods for Flow and Transport in Porous Media", 2003

${ }^{99} \mathrm{Nam}, \mathrm{K}$. , Jeong, S. : "Novel flow analysis of regenerator under oscillating flow with pulsating pressure ", CRYOGENICS 45 (5): 368-379 MAY 2005

${ }^{100}$ Tanaka, M., Yamashita, I., Chisaka, F. "FLOW AND HEAT-TRANSFER CHARACTERISTICS OF THE STIRLING ENGINE REGENERATOR IN AN OSCILLATING FLOW" JSME INTERNATIONAL JOURNAL SERIES II-FLUIDS ENGINEERING HEAT TRANSFER POWER COMBUSTION THERMOPHYSICAL PROPERTIES 33 (2): 283-289 MAY 1990

${ }^{101}$ Wood et. al, Sunpower Oscillating Flow Test Rig

${ }^{102}$ Saxer A.P., Giles M.B.: "Quasi-3-Dimensional Nonreflecting Boundary-Conditions For Euler Equations Calculations ", JOURNAL OF PROPULSION AND POWER 9 (2): 263-271 MAR-APR 1993

${ }^{103}$ Hagstrom T, Warburton T: "A new auxiliary variable formulation of high-order local radiation boundary conditions: corner compatibility conditions and extensions to first-order systems ", WAVE MOTION 39 (4): 327-338 APR 2004

${ }^{104}$ Modi, A., "Unsteady Separated Flow Simulations Using a Cluster of Workstations", Master's Thesis, Pennsylvania State University, May 1999

105 http://www.osc.edu/

${ }^{106}$ Sterling, Thomas Lawrence. "Beowulf cluster computing with Linux / [edited by] Thomas Sterling " QA76.58 .B46 2002 2002 Owned by: GODDARD IVV

${ }^{107}$ David HM Spector 1st ed. "Building Linux clusters : [scaling Linux for scientific and enterprise applications]" QA76.76 $.063 \mathrm{~S} 664720002000$

${ }^{108}$ http://www.top500.org/

${ }^{109} \mathrm{http}: / /$ www.dell.com/

$110 \mathrm{http}: / /$ www.angstrom.com/

${ }^{111}$ http://www.linuxnetworx.com/

112 http://www.appro.com/

$113 \mathrm{http}: / /$ www.microway.com/

${ }^{114}$ Ibrahim, M. "Personal Communication", April 2005.

${ }^{115}$ Schneider T., Botta N., Geratz K.J., Klein R. "Extension of finite volume compressible flow solvers to multi-dimensional, variable density zero Mach number flows", JOURNAL OF COMPUTATIONAL PHYSICS 155 (2): 248-286 NOV 11999

${ }^{116}$ Fluent User's Group Meeting 2005.

${ }^{117}$ http://www.stirlingtech.com/ 


\begin{tabular}{|c|c|c|c|}
\hline \multicolumn{3}{|c|}{ REPORT DOCUMENTATION PAGE } & $\begin{array}{l}\text { Form Approved } \\
\text { OMB No. 0704-0188 }\end{array}$ \\
\hline \multicolumn{4}{|c|}{ 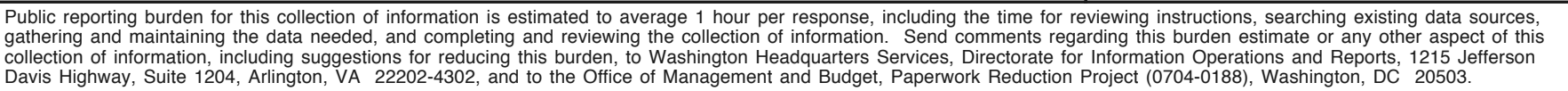 } \\
\hline 1. AGENCY USE ONLY (Leave blank) & $\begin{array}{l}\text { 2. REPORT DATE } \\
\text { October } 2005\end{array}$ & 3. $\mathrm{R}$ & $\begin{array}{l}\text { ID DATES COVERED } \\
\text { echnical Memorandum }\end{array}$ \\
\hline \multicolumn{3}{|c|}{$\begin{array}{l}\text { 4. TITLE AND SUBTITLE } \\
\text { Fast Whole-Engine Stirling Analysis }\end{array}$} & 5. FUNDING NUMBERS \\
\hline \multicolumn{3}{|l|}{ 6. AUTHOR(S) } & Rodger W. Dyson, Scott D. Wilson, Roy C. Tew, and Rikako Demko \\
\hline $\begin{array}{l}\text { 7. PERFORMING ORGANIZATION NA } \\
\text { National Aeronautics and Sp } \\
\text { John H. Glenn Research Cer } \\
\text { Cleveland, Ohio } 44135-31\end{array}$ & $\begin{array}{l}\text { S) AND ADDRESS(ES) } \\
\text { Administration } \\
\text { at Lewis Field }\end{array}$ & & $\begin{array}{l}\text { 8. PERFORMING ORGANIZATION } \\
\text { REPORT NUMBER } \\
\text { E-15276 }\end{array}$ \\
\hline $\begin{array}{l}\text { 9. SPONSORING/MONITORING AGEI } \\
\text { National Aeronautics and } \mathrm{Sp} \\
\text { Washington, DC 20546-00 }\end{array}$ & $\begin{array}{l}\text { VAME(S) AND ADDRESS(E } \\
\text { Administration }\end{array}$ & & $\begin{array}{l}\text { 10. SPONSORING/MONITORING } \\
\text { AGENCY REPORT NUMBER } \\
\text { NASA TM-2005-213960 } \\
\text { AIAA-2005-5558 }\end{array}$ \\
\hline \multicolumn{4}{|c|}{$\begin{array}{l}11 . \text { SUPPLEMENTARY NOTES } \\
\text { Prepared for the Third International Energy Conversion Engineering Conference sponsored by the American Institute of } \\
\text { Aeronautics and Astronautics, San Francisco, California, August 15-18, 2005. Rodger W. Dyson and Roy C. Tew, NASA } \\
\text { Glenn Research Center; Scott D. Wilson and Rikako Demko, Sest, Inc., 18000 Jefferson Park Road, Middleburg Heights, } \\
\text { Ohio 44130. Responsible person, Rodger W. Dyson, organization code RPT, 216-433-9083. }\end{array}$} \\
\hline
\end{tabular}

\begin{tabular}{|l|l|l|l|l}
\hline 12a. DISTRIBUTION/AVAILABILITY STATEMENT & 12b. DISTRIBUTION CODE
\end{tabular}

Unclassified - Unlimited

Subject Category: 20

Available electronically at http://gltrs.grc.nasa.gov

This publication is available from the NASA Center for AeroSpace Information, 301-621-0390.

13. ABSTRACT (Maximum 200 words)

An experimentally validated approach is described for fast axisymmetric Stirling engine simulations. These simulations include the entire displacer interior and demonstrate it is possible to model a complete engine cycle in less than an hour. The focus of this effort was to demonstrate it is possible to produce useful Stirling engine performance results in a time-frame short enough to impact design decisions. The combination of utilizing the latest 64-bit Opteron computer processors, fiber-optical Myrinet communications, dynamic meshing, and across zone partitioning has enabled solution times at least 240 times faster than previous attempts at simulating the axisymmetric Stirling engine. A comparison of the multidimensional results, calibrated one-dimensional results, and known experimental results is shown. This preliminary comparison demonstrates that axisymmetric simulations can be very accurate, but more work remains to improve the simulations through such means as modifying the thermal equilibrium regenerator models, adding fluid-structure interactions, including radiation effects, and incorporating mechanodynamics.

\begin{tabular}{|c|c|c|c|}
\hline \multicolumn{3}{|l|}{ 14. SUBJECT TERMS } & 15. NUMBER OF PAGES \\
\hline \multicolumn{3}{|l|}{ Stirling cycle analysis } & \begin{tabular}{|r}
34 \\
\end{tabular} \\
\hline $\begin{array}{l}\text { 17. SECURITY CLASSIFICATION } \\
\text { OF REPORT }\end{array}$ & $\begin{array}{l}\text { 18. SECURITY CLASSIFICATION } \\
\text { OF THIS PAGE }\end{array}$ & $\begin{array}{l}\text { 19. SECURITY CLASSIFICATION } \\
\text { OF ABSTRACT }\end{array}$ & 20. LIMITATION OF ABSTRACT \\
\hline Unclassified & Unclassified & Unclassified & \\
\hline
\end{tabular}



